\title{
Patterns of care at end of life for people with primary intracranial tumors: lessons learned
}

\author{
Abdulrahman Alturki, MD \\ Department of Epidemiology, Biostatistics and Occupational Health
}

McGill University, Montreal, Quebec, Canada

August 2013

A thesis submitted to the Faculty of Graduate Studies and Research in partial fulfillment of the requirements of the degree of Master of Science in Epidemiology

(C) Abdulrahman Alturki, 2013 


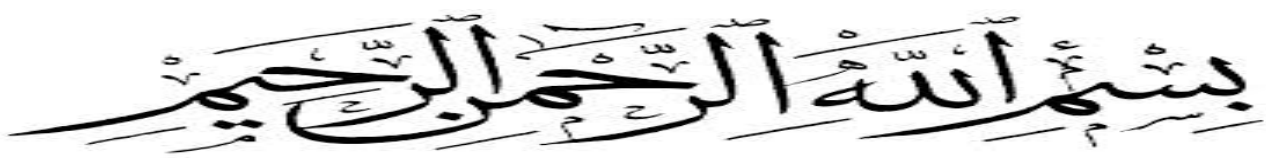

In the name of God, the Most Gracious, the Most Merciful. 


\section{Table of contents}
Abstract

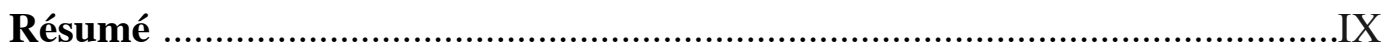

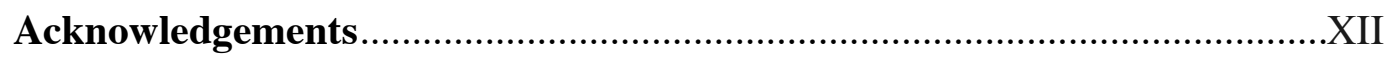
Preface \& contribution of authors.................................................................

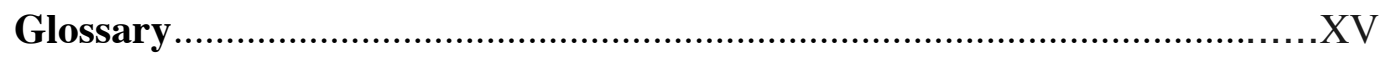

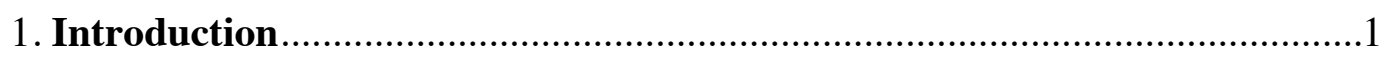

\section{Background}

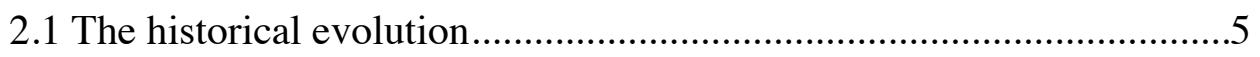

2.2 Why patients with intracranial tumors? ...............................................

2.3 Epidemiology of primary intracranial tumors .....................................11

2.4 Survival and quality of dying ………………..................................15

2.5 Service use and place of death........................................................22

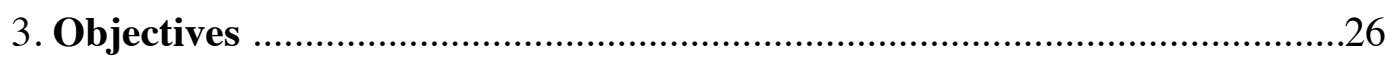

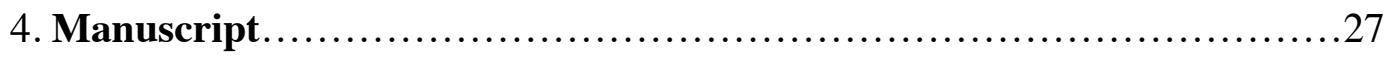

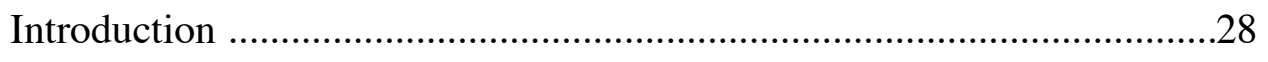

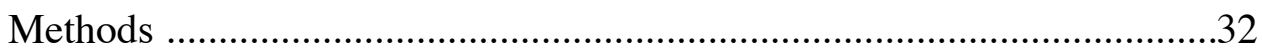

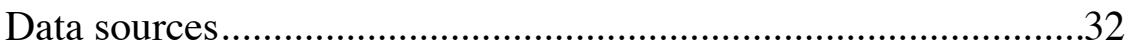

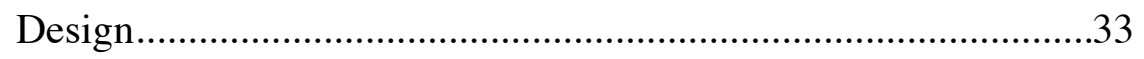

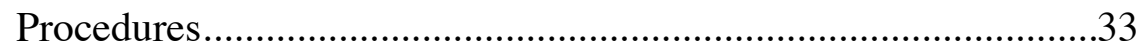

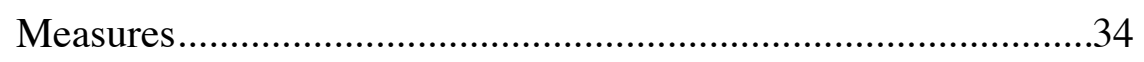

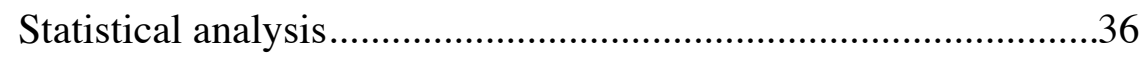


Results

Demographic characteristics.

.38

Factors modifying the level of care burden and place of death....39

Discussion .40

5. Discussion and conclusions.

6. References. .58

\section{Tables}

2-1 Methodological features of key studies on outcomes indicative of quality of dying and death. .25

4-1 Characteristics of the 1623 decedents from primary intracranial tumors

4-2 Distribution of the number of people receiving each type of health care encounters over the last six months of life.

4-3 Distribution of the number of people receiving each type of health care encounters over the last six months of life according to place of death....51

4-4 Cumulative proportional odds ratio (CPOR) estimating level of care burden (model 1) and place of death accounting for level of care burden (model 2) across different variables.

\section{Figures}

2-1 USA death rates for cancer and heart disease for ages younger than 85 years and 85 years and older, 1975 to 2006.

2-2 Age-specific incidence rates of primary brain and CNS tumors by selected histology 
2-3 Distribution of primary brain and CNS tumors by site.

2-4 Distribution of primary brain and CNS tumors by histology..... .14

2-5 Relative survival rates (primary brain tumors) by age group, ages $20+$,

12 SEER areas, 1988-2001 .16

2-6 Relative survival rates (primary brain tumors) by histology, ages $20+$,

12 SEER areas, 1988-2001. .16

2-7 Kaplan-Meier plot of maintaining functional independence for patients with glioblastomas .21

4-1 Identification of records for inclusion in the primary intracranial tumor end of life study

\section{Appendices}

1.Quality of end of life care, quality of life at the end of life, and quality of dying and death: concepts and domains.......

2. ICD-9 and ICD-10 codes defining included persons with a single intracranial tumor.

3. Histology codes defining included persons with primary intracranial tumors

4. Codes defining included persons with complication of primary intracranial tumors

5. Number of subjects per burden of care estimate. ..G 


\section{Abstract}

Background: One challenge facing practitioners managing the care and outcomes of persons with primary intracranial tumors is balancing reducing tumor burden while maintaining an acceptable quality of life, even until the end of life.

Administrative health databases have the unique potential of providing population-based, unbiased, efficient measures of quality of care especially in countries where population-based data are available.

The purpose of this study is to estimate, for people with primary intracranial tumors, the variability in processes of care (burden of care) experienced by patients in the last six months of life and potential predictors of place of death.

Methods: A death-backwards cohort was assembled using historical data. Three health administrative databases maintained by the province of Quebec, Canada were used to identify the cohort and the services provided during the last 6 months of life. The hospital discharge database (MedEcho), the physician fee-for service billings databases (RAMQ), and the death registry were accessed for the years 2003-2006 inclusive, to identify persons who died from primary intracranial tumors (or its complications).

An estimate of level of care burden was created using characteristics of care during the last 6 months of life based on: number intensive care unit (ICU) admissions, Emergency room (ER) visits, duration of hospital stay and 
interventions received. Predictors of level of care burden and place of death in this population were identified using ordinal logistic regression.

Results: A total of 1623 decedents were identified. $90 \%$ had at least one admission to an acute care hospital in the past 6 months and $23 \%$ spent 3 months or more of their last 6 months of life in hospital. $44 \%$ had one or more ER visits and $30 \%$ were admitted one or more times to ICU. In the last 6 months of life, only $18 \%$ had a home visit by a physician.

We found that $10 \%$ died at home, less than the reported average in the literature (>20\%); 49\% died in hospital (acute care unit/ ER/ chronic care), while $40 \%$ died in a palliative care facility (palliative care or hospice).

Older age group (70-79 years), high number of comorbidities, and being diagnosed with grade 4 Astrocytoma were associated with greater burden of care.

Level of care burden and older age group ( $\geq 70$ years) were associated with higher odds of dying in a more treatment intensive place of death (e.g. ER or acute care), being diagnosed with grade 4 Astrocytoma had the opposite effect.

Conclusion: The utilization of collected clinical information available in wellstructured administrative databases is accessible at a reasonable cost and allows the study of the whole population.

This study showed that despite valuable research efforts to improve the treatment of primary intracranial tumors that focus on tumor biology and refinements to 
surgery, radiation, and chemotherapy, there is also room to improve aspects of care in the end of life situation. An integrative approach for this patient's population, from diagnosis to death, could potentially reduce the care burden in the final period on the health care system, patient's family and improve access to a better place of death. 


\section{Résumé}

Contexte: Un des défis auxquels sont confrontés les praticiens en gestion de soins et les résultats des personnes atteintes de tumeurs intracrâniennes primaires est d'équilibrer la réduction de la charge tumorale tout en conservant une qualité de vie acceptable jusqu'au la fin de la vie.

Les bases de données administratives sur la santé offrent des mesures efficaces d'une population qui sont impartiales sur la qualité des soins en particulier dans les pays où les données basées sur la population sont disponibles.

Le but de cette étude est d'estimer la variabilité dans les processus de soins (fardeau des soins) vécue par les patients atteints de tumeurs intracrâniennes primaires dans les derniers six mois de leur vie et les facteurs prédictifs potentiels de la place de la mort.

Méthodes: Une cohorte mort-arrière a été assemblé à l'aide de données historiques. Trois bases de données administratives sur la santé tenues par la province de Québec (Canada) ont été utilisées pour créer la cohorte ainsi qu'identifier les services fournis au cours des 6 derniers mois de la vie. La base de données de congé de l'hôpital (MedEcho), les honoraires médicaux pour les bases de données des facturations de services (RAMQ), et le registre des décès ont été consultés pour les années 2003 à 2006 inclusivement, afin d'identifier les personnes qui sont mortes de tumeurs intracrâniennes primaires ou de leurs complications. 
Une estimation du niveau de charge des soins a été créé en utilisant les caractéristiques de soins au cours des 6 derniers mois de vie fondés sur l'unité de nombre de soins intensifs des admissions, le nombre de visite en salle d'urgence (ER), la durée de l'hospitalisation, ainsi que les interventions reçues. Les prédicteurs de niveau de charge des soins et les lieux de décès dans cette population ont été identifiés par régression logistique ordinale.

Résultats: Un total de 1623 personnes décédées ont été identifiées. 90\% des personnes avaient au moins une admission à un hôpital de soins de courte durée dans les 6 derniers mois et $23 \%$ ont passé 3 mois ou plus de leurs 6 derniers mois de vie en soins de courte durée. En outre, $44 \%$ ont eu une ou plusieurs visites à l'urgence et $30 \%$ ont été admis une ou plusieurs fois aux soins intensifs. Au cours des 6 derniers mois de la vie, seulement $18 \%$ ont eu une visite à domicile par un médecin.

Nous avons constaté que $10 \%$ sont décédés à la maison, soit moins que la moyenne rapportée dans la littérature (> 20\%); 49\% sont décédés à l'hôpital (soins Unite / ER / chronique soins de courte durée), tandis que $40 \%$ sont décédés dans un établissement de soins palliatifs (soins palliatifs ou de soins palliatifs).

Dans le groupe le plus âgé (70-79 ans), le nombre élevé de comorbidités et le diagnostique d'astrocytome de grade 4 sont associés à une plus grande charge de soins. 
Le niveau de charge des soins et le groupe d'âge ( $\geq 70$ ans) ont été associés à une plus grande probabilité de mourir dans un lieu de traitement intensif (par exemple ER ou soins aigus). Avoir été diagnostiqué avec astrocytome de grade 4 a eu l'effet inverse.

Conclusion: L'utilisation des données cliniques disponible dans des bases de données administratives bien structurées est accessible à un coût raisonnable et permet l'étude de l'ensemble de la population.

Cette étude demontre que, malgré les efforts de recherche pour améliorer le traitement des tumeurs intracrâniennes primaires axées sur la biologie des tumeurs la chirurgie, la radiothérapie et la chimiothérapie, il est également possible d'améliorer les aspects des soins en fin de vie. Une approche intégrée pour un patient, du diagnostic à la mort, pourrait réduire le fardeau des soins sur le système de soins de santé et la famille du patient tout en améliorant l'accès à une meilleure place de la mort. 


\section{Acknowledgements}

This project has become a reality thanks to Dr. Nancy Mayo, my thesis supervisor, who invited me to take advantages of an existing cohort of cancer patients. Under her constant and encouraging supervision, I was able to acquire the knowledge to handle and analyze administrative databases. I recognize in her a talented researcher and teacher. She provided me with continuous input during all the parts of the initial definition of the project, the statistical analyses, the interpretation of the models, the drafting of this thesis, and the presentation of the findings. I was privileged to be able to have my epidemiology training under her supervision.

I would like also to thank Drs. Kevin Petrecca (thesis so-supervisor), Bruno Gagnon, for their support and suggestions in carrying out this project. Dr. Petrecca suggestions and knowledge in Neuro-oncology were most helpful. Dr. Gagnon's pioneer work in patterns of care at end of life was an outstanding example for me to learn from.

This project would have not been possible without the constant support of Ms. Lyne Nadeau and Ms. Susan Scott who were always available to help me find my way through S.A.S. coding and programming. I therefore thank their patience and skills they put to help me in this endeavor.

I am indebted to Dr. Jeffrey Atkinson, my program director, Dr. Line Jacques (former program director), and Ms Luisa Birri, neurosurgery training program 
administrative assistant, for their exceptional support and easing the transition from my clinical duties as a neurosurgery resident to continue my studies.

Appreciation is also extended to Dr. Pierre Ernst and Dr. Judith Marcoux, for their advice, support and encouragement.

I would like to thank those not directly involved but whose support was nevertheless essential to this project in the neurosurgery departments at the Montreal Neurological Institute and at the National Neurosciences Institute, Saudi Arabia.

Finally, I could not even begin, or let alone finish this wonderful research journey, without the support and understanding of my family, my treasured parents: for making me believe that I could do anything I wanted in life, my beloved wife Maryam and my heroes Yaqub and Yussef: for their love and for bearing with my husband/father/resident/student status for the last two years.

Merci à vous tous, 


\section{Preface \& contribution of authors}

The structure of the thesis is a manuscript-based, which is supported by the McGill University faculty of graduate studies and research regulations for the "Guidelines for Thesis Preparation". The format of the manuscript-based thesis requires that the paper should have a cohesive, unitary character and a report of a single field of research.

The candidate functioned as principal investigator in the aspect of study design, operationalization of study variables, statistical analysis, interpretation of findings, and writing of the manuscripts. The co-authors of the manuscript were member of the supervisory committee, the division of clinical Epidemiology and the department of Neurosurgery at the McGill university health center. The candidate would be responsible for the scientific quality of the research, the accuracy of the data and the quality of reporting.

The data in this thesis are presented at its most granular level, for submission of the manuscript for publication, we might consider reducing the categories. 


\section{Glossary}

$\begin{array}{ll}\text { CLSC } & \text { Centre Local De Santé Communautaire } \\ \text { CPOR } & \text { Cumulative Proportional Odds Ratio } \\ \text { ER } & \text { Emergency Room } \\ \text { GBM } & \text { Glioblastoma Multiforme, Grade 4 Astrocytoma } \\ \text { HRQL } & \text { Health-related quality of life } \\ \text { ICD } & \text { International Classification of Diseases } \\ \text { ICU } & \text { Intensive Care Unit } \\ \text { MedEcho } & \text { Maintenance Et Exploitation Des Données Pour } \\ & \text { l'Étude De La Clientèle Hospitalière } \\ \text { PCU } & \text { Palliative Care Unite } \\ \text { RAMQ } & \text { Régie De l'Assurance Maladie Du Québec } \\ \text { SEER } & \text { The Surveillance, Epidemiology, and End Results } \\ & \text { Program } \\ \text { WHA } & \text { The United States of America } \\ & \text { World Health Organization }\end{array}$




\section{Introduction}

The WHO expert committee defined palliative care as "the active total care of patients whose disease is not responsive to curative treatment."

The goal of palliative care is the achievement of the best possible quality of life for patients and their families. Therefore, it applies to every cancer patient, either on its own or combined with active therapies. Clearly, palliative care goes beyond focusing on medical issues.

Palliative care programs have clearly improved the quality of life of patients with advanced cancer and their families. Reports on the value of hospices, home care programs, specialized palliative care teams in hospitals and regional programs have shown proven benefits to patients and families..$^{2-4}$

Promoting quality of life and reducing the burden of care to the patient are pivotal to the philosophy of end of life care. ${ }^{5}$ How much has this philosophy influenced the care received by patients with intracranial tumors?

Prospective studies, while optimal for this type of question, are very costly and difficult to carry out. A retrospective approach is an efficient tool to monitor end of life care across jurisdictions, demographic groups and time periods. ${ }^{6}$

Some researchers have used the collected clinical information available in administrative databases to study these clinical questions successfully. ${ }^{5}$ Such 
studies are feasible at a reasonable cost and allow the study of the whole population. ${ }^{7}$

Administrative health databases have the unique potential of providing population-based, unbiased, efficient measures of quality of care especially in countries where population-based data are available. ${ }^{8-10}$ A challenge is that the elements of care burden and palliative care are not directly documented in administrative databases.

However, certain elements of care that reflect provision of palliative care that have been identified as potential indicators of good quality of end of life cancer care can be extracted from administrative databases.

One feature of good end of life care is the possibility of a patient remaining at home and dying in relative comfort and dignity. In a prospective cohort study, Townsend et al showed that $67 \%$ of patients dying of cancer, given favorable circumstances, would prefer to die at home. ${ }^{11}$ Hays et al, found the same wishes in a study performed in a continuing-care retirement community, in which $62 \%$ of patients said they would prefer to die in their residence or nursing facility. ${ }^{12}$ Earle et al, in a study of potential indicators of good end of life cancer care, confirmed that home death is preferred, as opposed to hospital death. ${ }^{9}$ They also identified other indicators of poor-quality end of life cancer care like: frequent emergency department visits, high number of hospital and ICU days near the end of life, low proportion of patients admitted into hospice care or other non-acute care settings. 
What is the optimum time interval to study care at end of life? We would like to select a time interval that reflects the cancer evolution before death. In general, cancer patients experience a marked decline in their physical function in their last 6 months of life-especially true in brain tumor patients-, associated with increased symptom severity. ${ }^{13-15}$

In the case of cancer care, it is crucial to distinguish those who are:

1- dying of cancer

2- died of cancer treatment

3- died with cancer

Ascertaining the exact nature of disease causing the terminal state is a prerequisite for the study of patterns of care at the end of life, as patterns vary with different illnesses. ${ }^{16}$

Increasing attention has been focused on the need to improve quality of care at the end of life in cancer patients and existing data suggest that too many patients do not receive adequate supportive care in the last stage of disease. ${ }^{17,18}$ Assessing patterns of care is challenging given the scarcity of well-validated instruments, difficulty with compliance especially in longitudinal measurements over time, and the lack of well-designed trials. 
Assessing patterns of care in patients with intracranial tumors is additionally complicated by the relative rarity of the disease and complexity of care compared to other tumors.

The Québec's healthcare system provides the population with a wide range of services. Universal access to free healthcare services includes physicians and hospital medical services. Establish under the Act respecting health services and social services adopted in December 1971, the Québec health and social services system is mandated to maintain, improve and restore the health and welfare of the population by making a set of health services and social services accessible to them. ${ }^{19}$

Utilizing administrative databases available in the province of Québec, we decided to obtain information about patterns of care at the last 6 months of life for people diagnosed with primary intracranial tumors. 


\section{Background}

\subsection{The historical evolution}

Ancient physicians and surgeons knew that cancer would usually come back after it was surgically removed. The Roman physician Celsus (28-50 BC) wrote, "After excision, even when a scar has formed, none the less the disease has returned."20

On the other hand, Galen (130-200 AD) viewed cancer much as Hippocrates (460-370 BC) had, and his views set the pattern for cancer management for centuries: he considered the patient incurable after a diagnosis of cancer had been made.

Even though medicine progressed and flourished in some ancient civilizations, there was little progress in cancer treatment. The approach to cancer was Hippocratic (or Galenic) for the most part. To some extent the belief that cancer cannot be completely cured has persisted even into the 21 st century. This has served to fuel the fear people have of the disease. Some people, even today, consider all cancer incurable and put off seeing a doctor until it is too late for optimal treatment. ${ }^{21,22}$

Cancer treatment has gone through a slow process of development. The ancients recognized that there was no curative treatment once a cancer had spread, and that intervention might be more harmful than no treatment at all. Galen did write about surgical cures for breast cancer if the tumor could be completely removed at an early stage. Surgery then was very primitive with many complications, including 
blood loss. It wasn't until the 19th and early 20th centuries that major advances were made in general surgery and cancer surgery. ${ }^{23}$

In 1761, Giovanni Morgagni of Padua was the first to do something, which has become routine today, he did autopsies to relate the patient's illness to pathologic findings after death. This laid the foundation for scientific oncology, the study of cancer. ${ }^{24}$ When anesthesia became available in 1846 , the surgical oncology advanced so rapidly that the next hundred years became known as "the century of the surgeon."

Knowledge and cancer treatment evolved: in 1895, the discovery of X-rays and in 1898 , the discovery of radioactivity brought many changes in treatments; later during World War II- the discovery of nitrogen mustard, a chemical warfare agent, as an effective treatment for cancer. Since then, chemotherapy has played an important role in the battle against cancer..$^{25}$

It has been more than 40 years since President Nixon proposed, in his 1971 State of the Union address, to “ . . launch an intensive campaign to find a cure for cancer. . . "26 . Despite very substantial investment and effort over the past few decades, the overall survival rate of cancer patients has changed little. ${ }^{27}$

Cancer is expected to surpass cardiovascular diseases as the leading cause of death in the world by 2010, according to the World Health Organization's World Cancer Report $2008 .^{28}$

In Canada, from 2000 to 2009, deaths caused by major cardiovascular diseases 
have declined, while deaths caused by cancer have increased. Since 2007 cancer has surpassed major cardiovascular diseases for number of deaths and the gap between these two causes of death has widened. ${ }^{29}$

Figure 2-1 shows death rates for cancer and heart disease for ages younger than 85 years and 85 years and older, 1975 to $2006 .^{30}$

Advances in technology have made earlier diagnosis possible, management is increasingly multimodal and multidisciplinary, and the population is aging especially in the high-income societies. These secular changes have increased the complexity of care and the diversity of the population seeking care, even more so, regarding the care of the dying. 

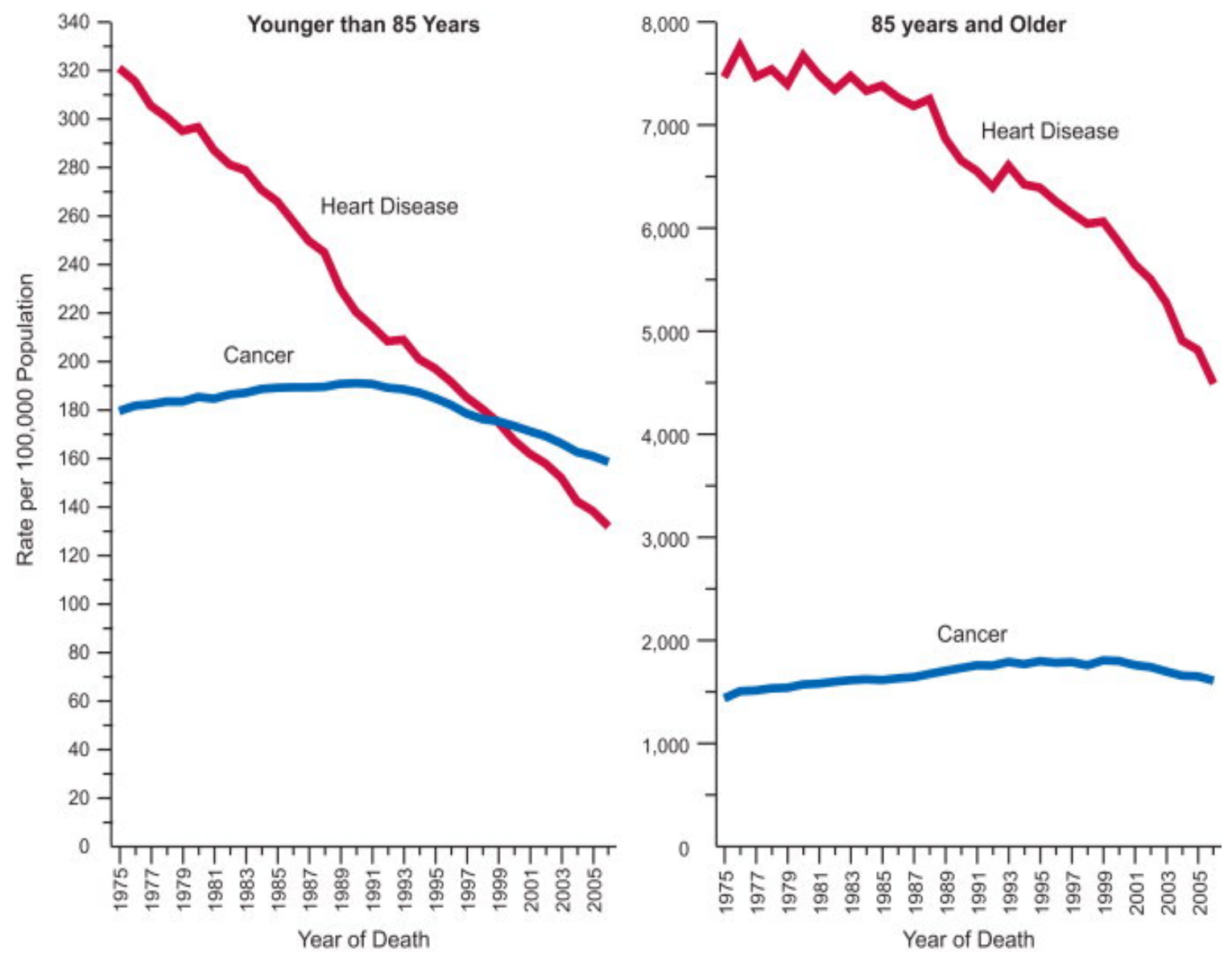

Figure 2-1. USA death rates for cancer and heart disease for ages younger than 85 years and 85 years and older, 1975 to 2006. 


\subsection{Why patients with intracranial tumors?}

"I put it to the House that the issue of brain tumors is under-debated, under-reported and under-funded. In this Parliament, the issue has attracted minimal-dare I say it, derisory-attention... A score of charities through a plethora of fund-raising methods - finance research. In short, there is no ground whatsoever for complacency. In any case, charitable effort can only ever be a supplement to, not a substitute for, public financial support. That support is needed, needed on a substantial scale, and needed now."

This admonishment came from John Bercow, chair of the brain tumor all party parliamentary group, House of Commons (UK) in April 2004.

One of the difficult challenges facing the practitioners managing the care and outcomes of persons with primary intracranial tumors is balancing reducing tumor burden while maintaining an acceptable quality of life even until the end of life.

In spite of aggressive multimodality treatment with surgery, radiotherapy, and chemotherapy, the prognosis of patients with primary or metastatic intracranial tumors remains poor-compared to other tumors-, especially for those affected by malignant tumors. While developments of more active treatments are ongoing, physicians looking after patients with intracranial tumors have the important role of providing effective and adequate supportive care for symptoms and 
complications that may result directly from the tumor or indirectly from its treatment. ${ }^{31,32}$

People with intracranial tumors have the same "general tumor symptoms" as people with other types of tumors, but they also experience consequences of focal neurological deficits, such as motor deficit, aphasia or visual field defects. Because of these sequelae, the functional impact of intracranial tumors is much more widespread than the impact of other types of cancers.

In the last stage of disease, patients with intracranial tumors may become functionally dependent due to the growing tumor or to treatment side effects, indicating even greater need for palliative and supportive care. ${ }^{33,34}$ In the palliative care setting, people with intracranial tumors report the most severe symptoms and concerns. ${ }^{35}$ Thus, it is clear that the complex care needs of patients with intracranial tumors and their families in advanced stages of disease should be managed by well-trained multidisciplinary teams who are prepared to meet the needs of this population. ${ }^{36}$ 


\subsection{Epidemiology of primary intracranial tumors}

In the United States from 2005 to 2009, the average annual age-adjusted incidence rate over all primary brain and CNS tumors was 20.59 per 100,000 . At a state level, the rates of primary malignant brain and CNS tumors ranged from 4.95 to 8.97 per 100,000 , and 8.90 to 19.02 per 100,000 , for non-malignant. Rates are higher in women $(22.3$ per 100,000$)$ than men $(18.8$ per 100,000$) .^{37}$ Rates also increase with increasing age (see Figure 2-2). The most common sites of primary brain tumors are meninges and pituitary (see Figure 2-3). The most common malignant tumor is glioblastoma (GBM; synonymous with an astrocytoma grade IV tumor) and the most common non-malignant (benign) tumor in adults is meningioma (see Figure 2-4). Fortunately malignant brain tumors are rare accounting for only $1 \%$ to $2 \%$ of all adult cancers. Incidence, response to treatment, and survival after diagnosis vary greatly by age at diagnosis, histologic type of tumor, and degree of neurologic compromise. ${ }^{38}$

In Canada, the estimated number of people with new malignant brain cancers was 2,800 for 2012 , with an age-standardized incidence rate of 7 per $100,000 .^{39}$

The worldwide incidence rate of primary malignant brain and CNS in 2008, ageadjusted using the world standard population, was 3.1 per 100,000 in women and 3.8 per 100,000 in men. This represented an estimated 111,098 women and an estimated 126,815 men diagnosed with a primary malignant brain tumor in 2008, for an overall total of 237,913 individuals. The incidence rates were higher in 
more developed countries (men: 5.8 per 100,000; women: 4.4 per 100,000) than in less developed countries (men: 3.2 per 100,000; women: 2.8 per 100,000). ${ }^{40}$

The prevalence rate for all primary brain and CNS tumors was estimated to be 221.8 per 100,000 (61.9 per 100,000 for malignant; 177.3 per 100,000 for nonmalignant) in 2010. It was estimated that more than 688,096 persons were living with a diagnosis of primary brain and central nervous system tumor in the United States in 2010 (malignant tumor: more than 138,054 persons; non-malignant tumor: more than 550,042 persons) ${ }^{41}$

Reviews conclude that little is known concerning the etiology of brain tumors in adults. ${ }^{42,43}$ Studies continue to speculate that brain tumors might result from workplace, dietary, and other personal and residential exposures. Studies of cell phone use and power frequency electromagnetic fields have found little to support a causal connection with brain tumors. Some persons have an inherited predisposition to developing brain tumors is well established, and detailed study of cancer-prone families has yielded valuable insights into molecular mechanisms. However, documented genetic syndromes that predispose to brain tumors are quite rare, and familial clustering of brain tumors also is uncommon, thus implying a substantial role for non-heritable determinants. The one environmental exposure that has been shown unequivocally to cause brain tumors, namely ionizing radiation, probably is not responsible for more than a small fraction of brain tumors occurring today. ${ }^{42}$ The only proven causes of brain tumors (that is, rare hereditary syndromes, therapeutic radiation, and immune 
suppression giving rise to brain lymphomas) account for a small proportion of cases. $^{43}$

CBTRUS Statistical Report: NPCR and SEER Data from 2005-2009

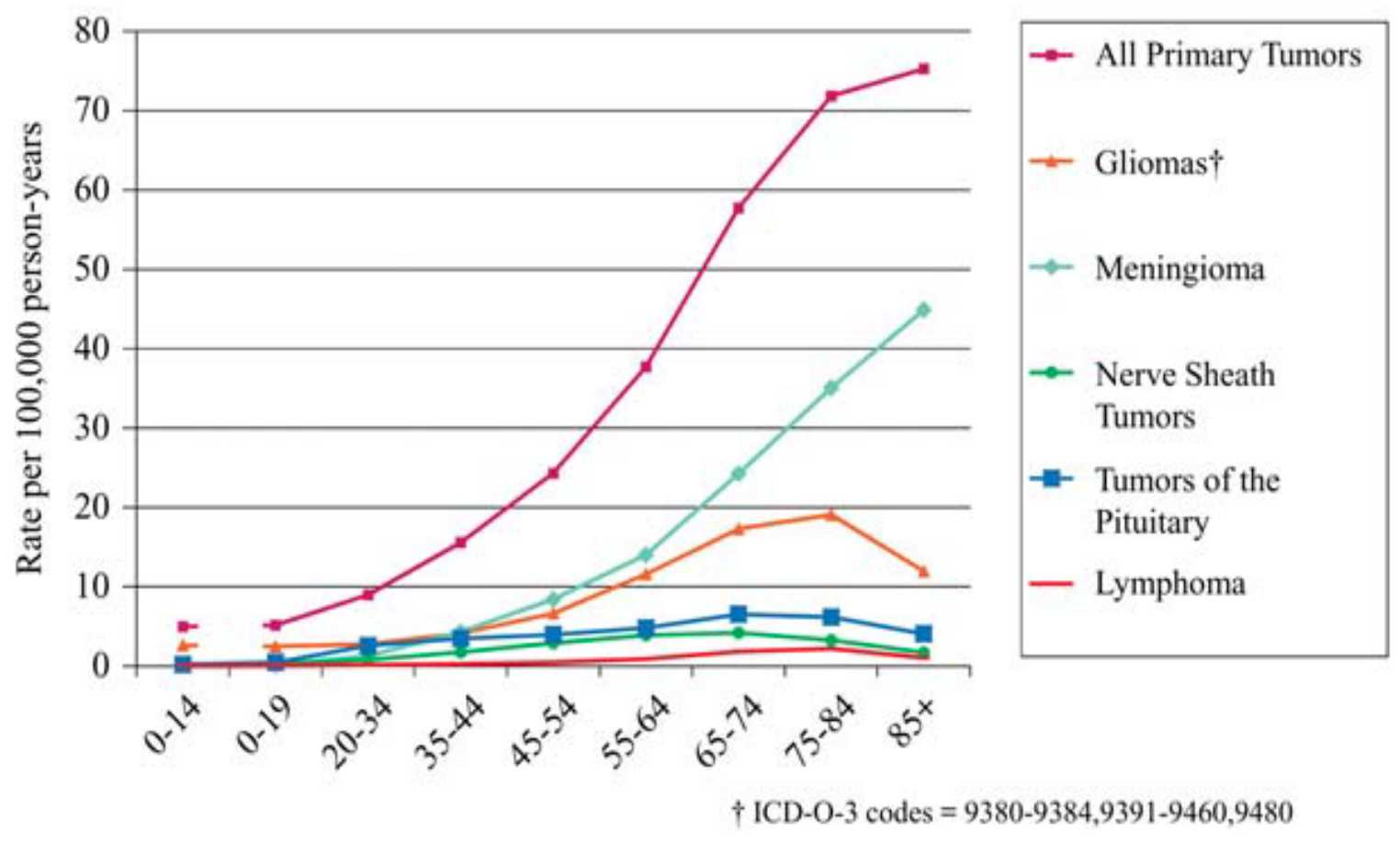

Figure 2-2: Age-specific incidence rates of primary brain and CNS tumors by selected histology. (USA) 


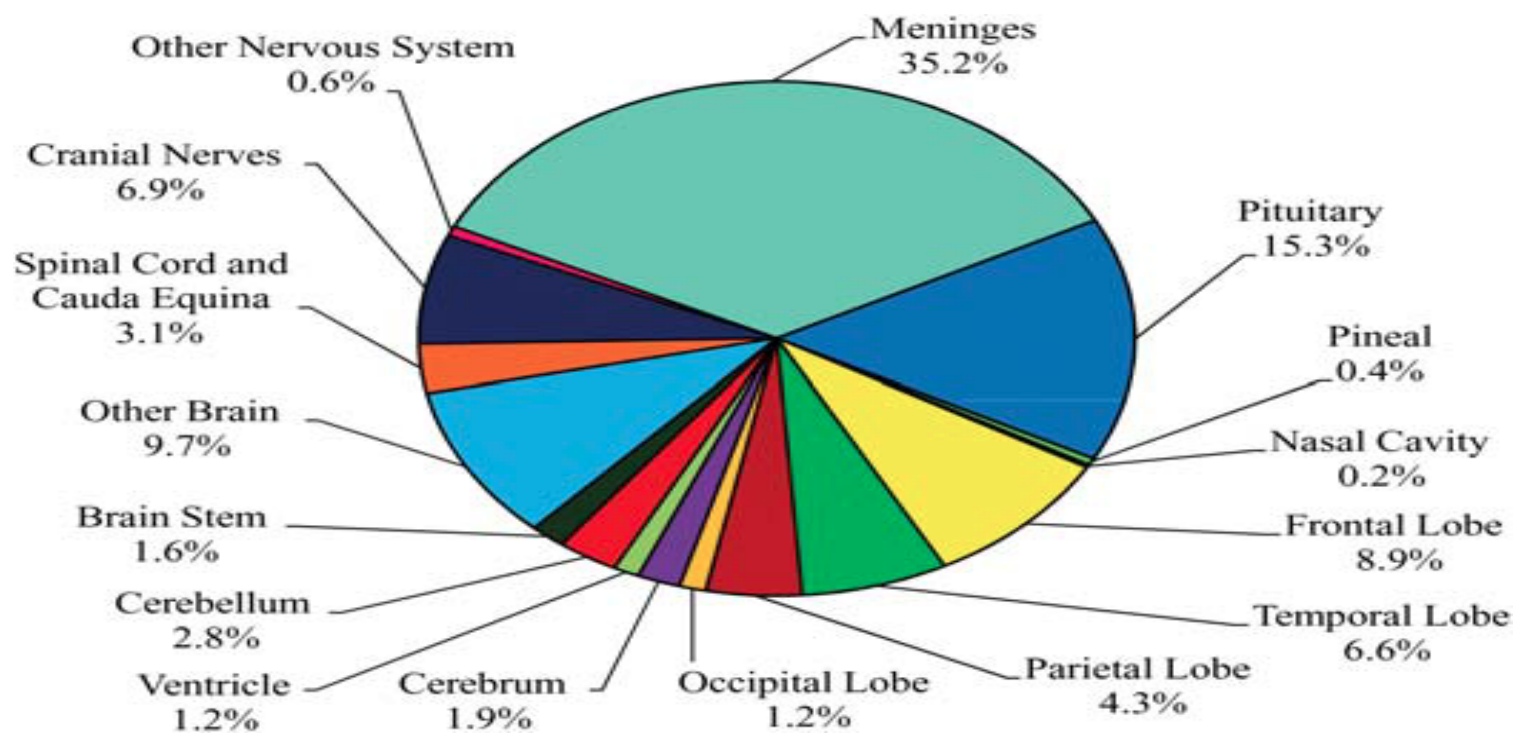

Figure 2-3: Distribution of primary brain and CNS tumors by site (N. 311,202).

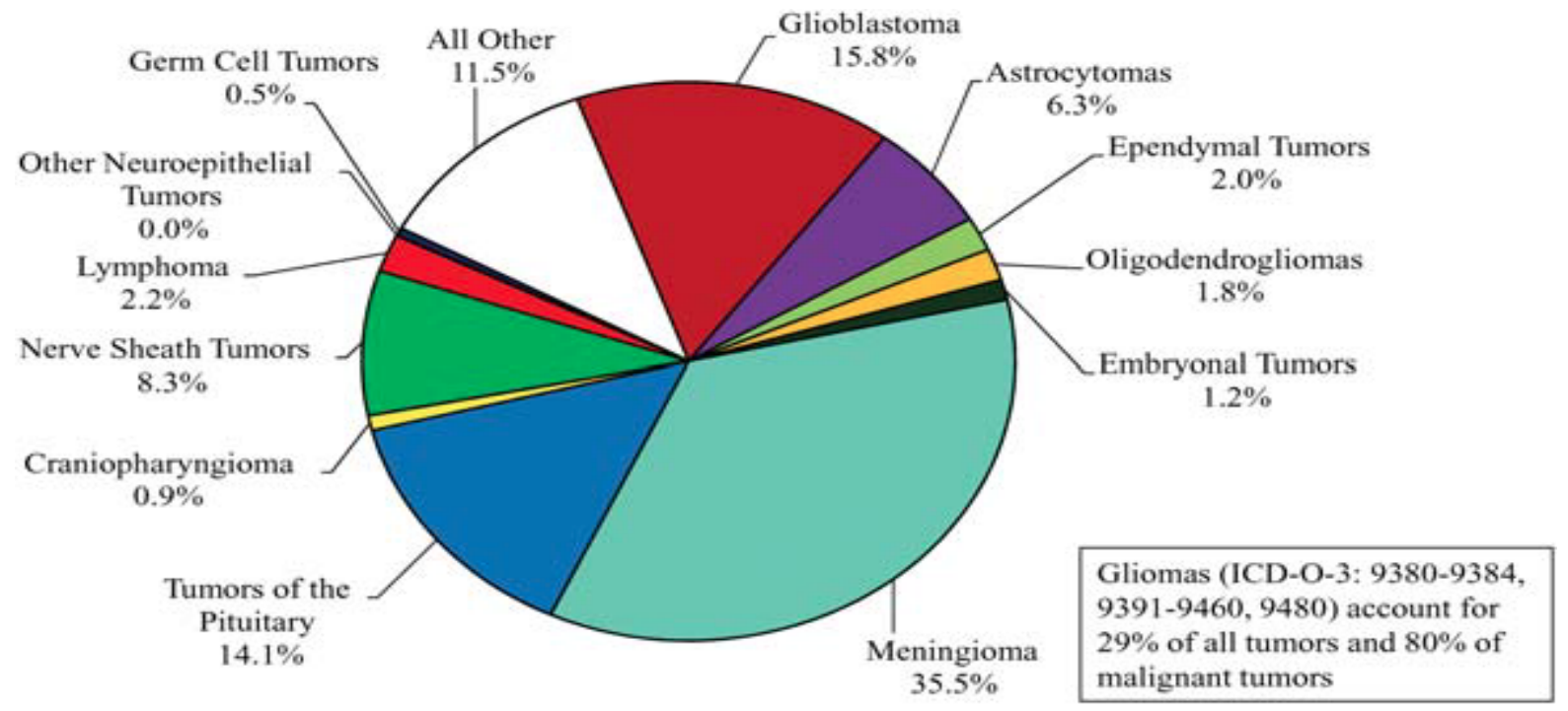

Figure 2-4: Distribution of primary brain and CNS tumors by histology (N.

$311,202)$. (USA) 


\subsection{Survival and quality of dying}

\section{Survival}

Only a few decades ago, the prognosis for people facing cancer was not nearly as favorable as it is today. During the 1970s, about 1 of every 2 people diagnosed with cancer survived at least 5 years. Now, more than 2 of every 3 survive that long. Today there are more than 11 million cancer survivors in the United States alone. $^{23}$

The length of survival following diagnosis of an intracranial tumor is dependent on the age of the patient, histologic subtype, grade of the tumor, and presenting symptoms. Survival chances have improved gradually over the last 30 years but still remain poor. The estimated five and ten years relative survival rates ${ }^{1}$ for malignant brain tumors are $33.7 \%$ and $27.9 \%$ respectively. However, there is a large variation in those estimates due to the factors mentioned above. For example, five year survival rates for a benign tumor, pilocytic astrocytoma (grade one), are $94 \%$ but are less than $5 \%$ for a malignant tumor, glioblastoma (grade four). ${ }^{38}$ Figures 2-5 and 2-6 shows relative survival rates by age group and histology respectively, ages $20+, 12$ seer areas, 1988-2001. ${ }^{44}$

A Canadian retrospective review by Bussière et al noted that the most important factors associated with time until death included age, severity of comorbidities,

\footnotetext{
1 The net survival measure representing cancer survival in the absence of other causes of death. Relative survival is defined as the ratio of the proportion of observed survivors in a cohort of cancer patients to the proportion of expected survivors in a comparable set of cancer free individuals. The formulation is based on the assumption of independent competing causes of death.
} 
pretreatment performance status, presence of confusion, histopathological diagnosis, and type of treatment received. ${ }^{45}$

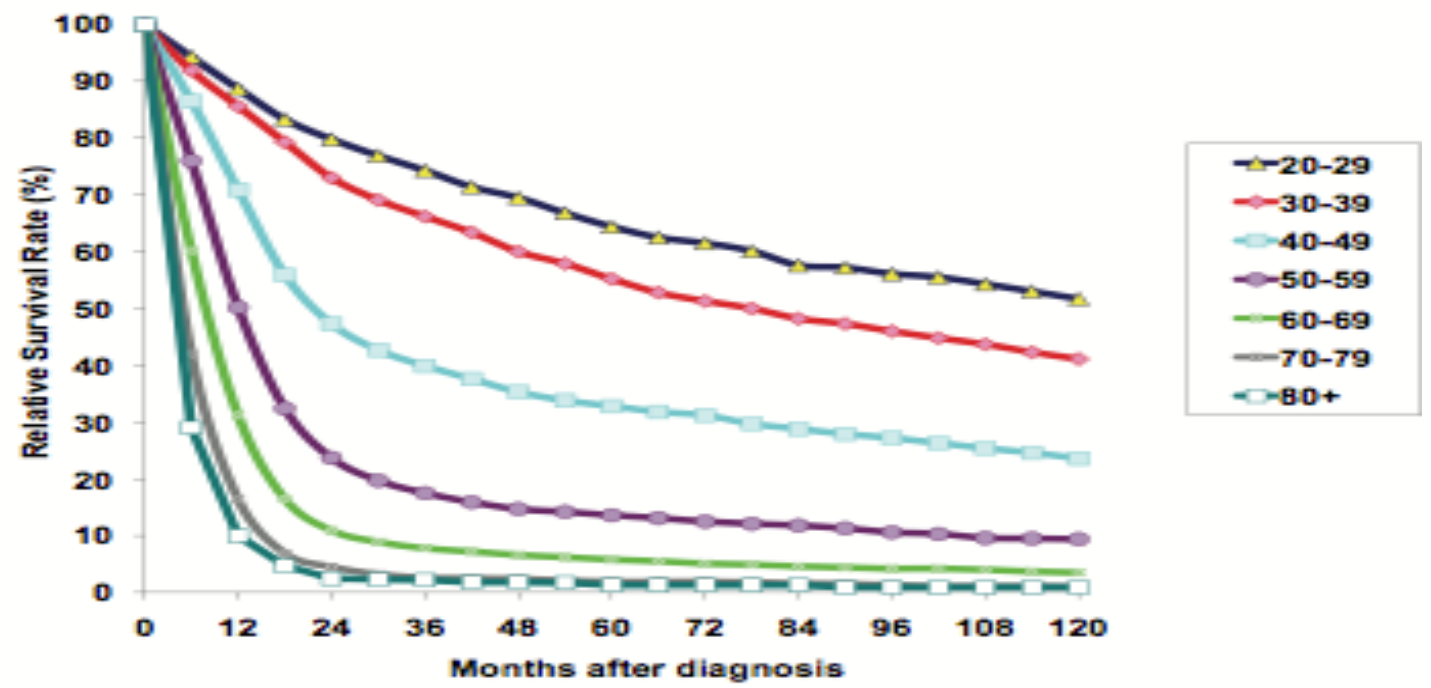

Figure 2-5: Relative survival rates (primary brain tumors) by age group, ages $20+$, 12 SEER areas, 1988-2001.

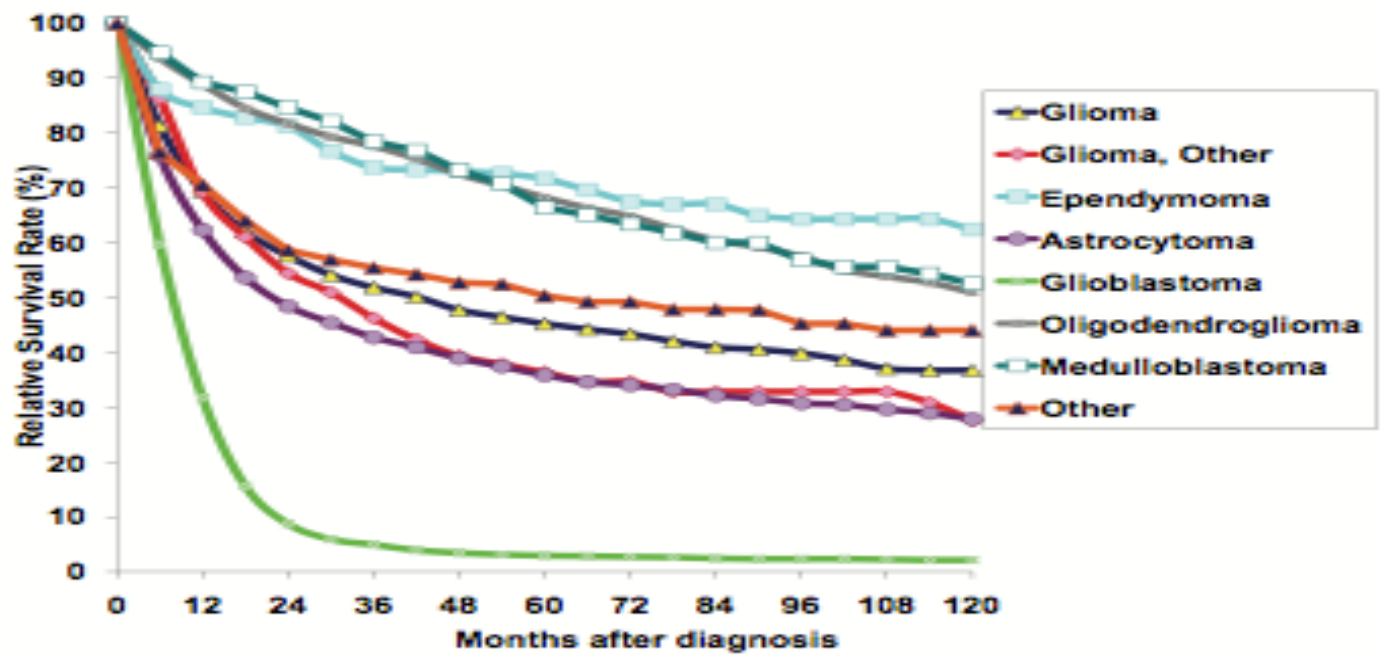

Figure 2-6: Relative survival rates (primary brain tumors) by histology, ages $20+$, 12 SEER areas, 1988-2001. 


\section{Present knowledge in end of life care and quality of dying}

The institute of medicine committee on end of life care defined the notion of highquality dying as a death "free from avoidable distress and suffering for patients, families, and their caregivers; in general accord with the patients' and families' wishes; and reasonably consistent with clinical, cultural, and ethical standards" ${ }^{» 46}$

Improving end of life experience is a major challenge to successful aging. Deaths that are reasonably free of discomfort, in accordance with patients' wishes, and within acceptable professional and ethical standards, are considered high-quality deaths.

Patrick et al have defined quality of dying and death under three sub-definitions: quality of end of life care, quality of life at end of life and quality of dying and death. ${ }^{47,48}$ These domains and concepts represent the quality of the dying experience. (Appendix 1)

A recent review by Ford et $\mathrm{a}^{49}$ (from 2005 through 2011) on the psychosocial and supportive needs of patients with primary malignant brain tumors and their families or caregivers showed that rates of depression and anxiety occur in up to $48 \%$ in patients and up to $40 \%$ in caregivers. The review indicated that there were many unmet needs and there was dissatisfaction with health care provider communication and information. Cognitive deficits, which increased as the disease progressed, also hampered communication and decision-making. It was also evident that there was a range of neurological and physical symptoms at the 
end of life that needed recognition and consideration for intervention, as there are some successful supportive and neuropsychological interventions.

Jalali et $\mathrm{al}^{50}$, in a recent review of factors influencing health-related quality of life (HRQL) in adults with primary brain tumors (benign and malignant), concluded that the nature of the tumor was the major factor influencing cognitive decline and HRQL. Patients with controlled disease had the most number of HRQL domains preserved, in comparison to those with disease progression. The specific tumorrelated factors influencing HRQL scores were tumor site, laterality, size, hypothalamic involvement, hormonal disturbances, and seizures. Interventions also took a toll on HRQL: exposure to anticonvulsants, corticosteroids, higher dose of radiation therapy, and chemotherapy. In high-grade gliomas, the literature supported that complete surgical resection followed by radiation therapy was associated with preservation of HRQL. In low-grade gliomas with loco-regional control, low dose per fraction radiation therapy was supported as preserving and even improving HRQL. Socioeconomic and cultural factors also played a role in HRQL likely through the availability of material and personal resources.

Table 2-1 presents methodological features of key studies on outcomes indicative of quality of dying and death. There is a common agreement that at the end of life, patients with advanced intracranial tumors experience the same disabling sequelae as persons with other types of tumors (fatigue, loss of appetite, shortness of breath, anxiety, depression, among others), but they have an additional burden related directly to the tumor site, including drowsiness, loss of consciousness, 
seizures, dysphagia, nausea/vomiting, and headache. ${ }^{51-54}$ This group of patients also has motor sequelae affecting balance, co-ordination, ambulation, and ability to do basic activities of daily living. For example, as shown by the studies in table $2-1$, more than $85 \%$ of terminally ill patients affected by intracranial tumors experience significant drowsiness and loss of consciousness. Also they commonly have generalized weakness $(62 \%-80 \%)$, headache $(33 \%-62 \%)$, seizures $(>30 \%)$, and difficulty swallowing $(>50 \%)$.

Cognitive impairment, a common sequlae of intracranial tumors, is very distressing for patients and family and it also interferes with communication, comprehension, and decision-making. Cognitive deterioration might be an early marker of disease progression or recurrence. ${ }^{55}$ Bussière et al noted that the most important prognostic factors for preserved functional status were age, pretreatment performance status, and type of treatment received. ${ }^{45}$ Chaichana and his group evaluated the functional independence (defined as the ability to conduct normal activity with the ability to attend to most personal needs) of 544 patients over time after glioblastoma resection and further treatments as indicated (chemotherapy and radiotherapy) and found that the median time for maintaining functional independence was 10 months, whereas the 6-, 12-, and 18-month functional independence rates were $68 \%, 41 \%$, and $27 \%$, respectively. (Figure 2 7). ${ }^{56}$

In studies examining the unmet needs of patients, more information and having access to a single, dedicated health care provider, were high on the list. In 
addition, the importance of effective communication between health care providers and caregivers was prominent, as inevitably caregivers become the primary decision-makers. In the same line, studies suggested that family caregivers experience high rates of stress and anxiety and that the economic burden of coping with disease may contribute to depression and emotional burden. Descriptive studies showed that family members are required to give “extraordinary uncompensated care" for months or even years. ${ }^{57,58}$

Janda and his research group have conducted interviews with patients and family caregivers, they named the top five unsupported tumor-specific needs reported by patients with intracranial tumors, were the physical adverse effects of the tumor and treatment, changes in their mental abilities, feeling as if they were not the same person, wanting information on the latest developments in research and treatment, and changes in their ability to work..$^{59}$

Now that more people are surviving cancer, more attention than ever is focused on the quality of life and long-term outcomes of cancer survivors. 


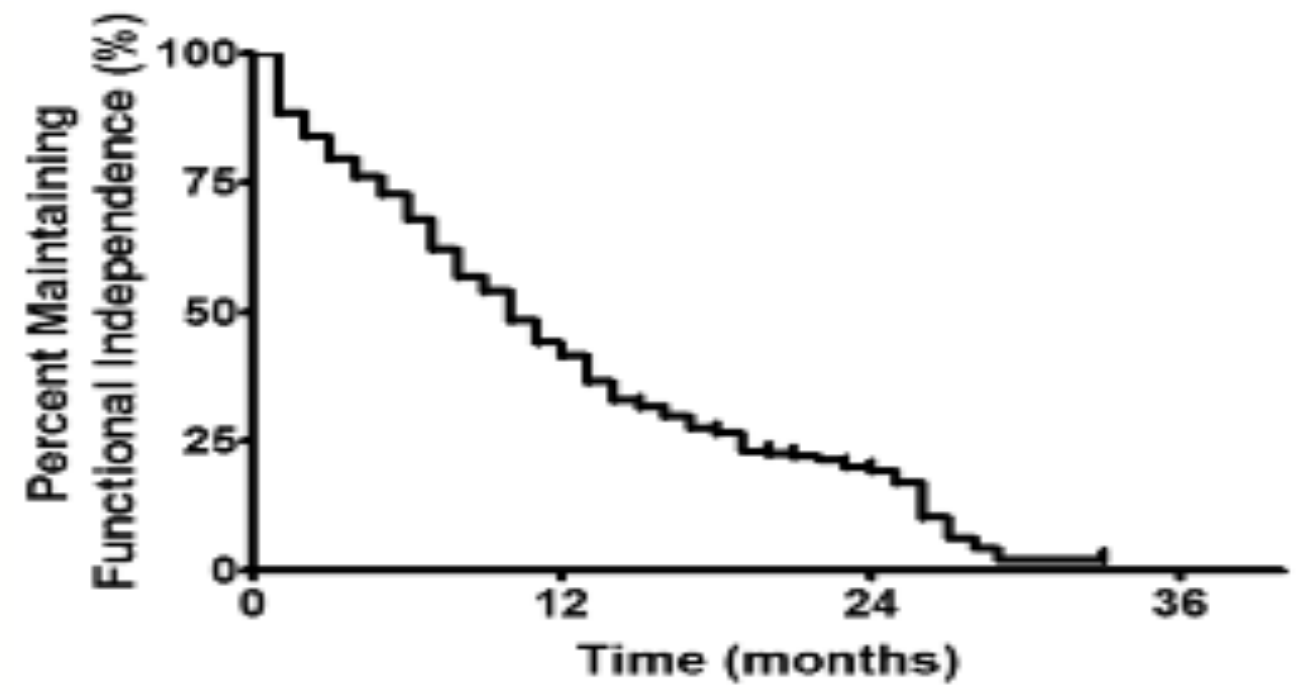

Figure 2-7: Kaplan-Meier plot of maintaining functional independence for patients with grade 4 Astrocytoma (glioblastomas). 


\subsection{Service use and place of death}

In a report from the institut national de santé publique du Québec, the need for palliative care for people who died of cancer was estimated at $45 \%$, in the province of Quebec, for the years 1997 to 2001. Off these cancer patients, 2.5\% were affected by brain primary tumors. ${ }^{60}$

In the same report, the place of death for people with primary brain tumors was found to be $8.6 \%$ at home, $6.1 \%$ home care, $11.6 \%$ at long-term care facility, and $71.9 \%$ in a general or specialized care setting.

A study from Germany, with an observation period of 17 months (2004 and 2005), looked at hospital bed utilization (982 beds) in one of the largest centers in Europe. At the time of the study, the hospital had no specialized palliative care service for in-house consultations and no palliative care unit. Data were collected prospectively and each patient discharged from the hospital was screened by surveying the treating physician who was responsible for dismissal about patients' palliative care needs (PCNs) based on the WHO 1990 definition of palliative care.

With a response rate of $96 \%$ and data from 39,849 patients, they found that a total of $6.9 \%$ of all hospital patients and $9.1 \%$ of patients older than age 65 years were considered to have PCNs. Of the 2,757 patients with PCNs, 67\% ( $\mathrm{n}=1836$ ) had cancer. Among the 11,584 patients with cancer, $15.8 \%$ were classified as having PCNs. PCNs were particularly high in patients with head and neck cancer (28.3\%), malignant melanoma (26.0\%), and brain tumors (18.2\%). ${ }^{61}$ 
The most common reasons for patients with advanced primary brain malignancies to be admitted to an acute care hospital in the last weeks of life were difficulties with care at home due to immobility (45\%), an acute change in the patient's clinical condition $(27 \%)$, and seizures $(13 \%) .^{54}$

The type of care given during the course of their illness among patients in palliative care units was summarized by Arber. ${ }^{62}$ Overall, $28 \%$ of patients were admitted to a hospice inpatient unit and $15 \%$ to acute inpatient services. For outpatient care, $11 \%$ of patients attended oncology outpatient appointments, $49 \%$ accessed community district nursing services, $7 \%$ accessed other voluntary-based services, $24 \%$ attended day hospice, and $36 \%$ were referred to social services for help with activities of daily living. Patients also accessed physiotherapy (35\%) and occupational therapy (31\%), and $34 \%$ of patients received financial benefits. Complementary therapies were used by $24 \%$ of patients, $35 \%$ used counseling services, and $13 \%$ accessed chaplains or church support. This study suggested that some patients were accessing specialist palliative care late, which may have implications for getting access to supportive care.

Access to community palliative care services for people with primary malignant brain tumors was reviewed in a UK study. The vast majority did so after cessation of active therapy. Within this group of patients, only half benefitted from inpatient hospice services while $74 \%$ were re-admitted to local acute care hospitals for management of symptom crises. ${ }^{63}$

Preferred place of death was elicited by a 2003 survey from the National Council 
for Hospice and Specialist Palliative Care Services (UK) (NCHSPCS). Overall, $56 \%$ of respondents, if dying, would want to be cared for at home and $24 \%$ would want to be cared for in hospices. Only $11 \%$ wanted to be cared for and die in hospital, with $4 \%$ wanting to die in a nursing home. The reality in practice is very different, with $25 \%$ of cancer patients dying in their own home, $17 \%$ in hospices, $47 \%$ in hospital and $12 \%$ in a nursing home. It was reassuring that a high proportion of those reviewed with primary malignant glioma were able to die at home $(33 \%)$ despite the high acute admission rate during the period of illness. ${ }^{64}$

When asked what would improve supportive care for patients, the 5 top suggestions from clinicians were having well-resourced specialist nurse availability, providing better community support for families, having better access to physiotherapy, having more integrated services and/or team clinics, and having better access to psychologists or counselors. ${ }^{65}$

For brain tumors, and or neurological diseases generally, early initiation of palliative interventions has the potential to improve quality of life, enhance symptom management and assist in advance care planning. ${ }^{66}$

One of the challenges in the literature related to services at end of life is inconsistent use of terms such as palliative care, supportive care, and end of life care. While there is a standard definition of palliative care by the WHO, the terms supportive care and end of life care are used less consistently. 
Table 2-1: Methodological features of key studies on outcomes indicative of

\section{quality of dying and death}

\begin{tabular}{|c|c|c|c|c|c|c|c|}
\hline \multirow{6}{*}{$\begin{array}{l}\text { Focus on } \\
\text { symptoms } \\
\text { and } \\
\text { quality of } \\
\text { life }\end{array}$} & Study & $\begin{array}{l}\text { Study } \\
\text { design }\end{array}$ & $\mathrm{N}$ & Setting & $\begin{array}{l}\text { Type of } \\
\text { intracranial } \\
\text { cancer }\end{array}$ & $\begin{array}{l}\text { Starting } \\
\text { point }\end{array}$ & $\begin{array}{l}\text { Time } \\
\text { reviewed } \\
\text { before } \\
\text { death }\end{array}$ \\
\hline & Pace et al, ${ }^{51}$ & $\begin{array}{l}\text { Chart } \\
\text { review }\end{array}$ & 324 & $\begin{array}{l}\text { Home care } \\
\text { program }\end{array}$ & $\begin{array}{l}\text { Mixed } \\
\text { primary \& } \\
\text { metastatic }\end{array}$ & $\begin{array}{l}\text { After } \\
\text { discharge } \\
\text { from acute } \\
\text { care }\end{array}$ & $\begin{array}{l}\text { Last } 2 \\
\text { months }\end{array}$ \\
\hline & $\underset{52}{\text { Sizoo et al, }}$ & Qualitative & 55 & $\begin{array}{l}\text { Telephone } \\
\text { interviews }\end{array}$ & $\begin{array}{l}\text { High-grade } \\
\text { Gliomas }\end{array}$ & $\begin{array}{l}\text { Refusal or } \\
\text { no further } \\
\text { tumor } \\
\text { treatment }\end{array}$ & $\begin{array}{l}\text { Not } \\
\text { specified }\end{array}$ \\
\hline & $\begin{array}{l}\text { Pelletier et } \\
\text { al, }{ }^{53}\end{array}$ & $\begin{array}{l}\text { Cross- } \\
\text { sectional }\end{array}$ & 60 & $\begin{array}{l}\text { Single site } \\
\text { brain tumor } \\
\text { clinic }\end{array}$ & $\begin{array}{l}\text { Mixed } \\
\text { primary }\end{array}$ & $\begin{array}{l}\text { Follow up } \\
\text { visits to } \\
\text { the clinic }\end{array}$ & $\begin{array}{l}\text { Not } \\
\text { specified }\end{array}$ \\
\hline & $\begin{array}{l}\text { Oberndorfer } \\
\text { et al, }{ }^{54}\end{array}$ & $\begin{array}{l}\text { Chart } \\
\text { review }\end{array}$ & 29 & $\begin{array}{l}\text { Single site } \\
\text { inpatient }\end{array}$ & Glioblastoma & $\begin{array}{l}\text { Admission } \\
\text { leading to } \\
\text { death }\end{array}$ & $\begin{array}{l}\text { The last } \\
10 \text { weeks }\end{array}$ \\
\hline & $\begin{array}{l}\text { Arber et } \\
\mathrm{al}^{62}\end{array}$ & $\begin{array}{l}\text { Chart } \\
\text { review }\end{array}$ & 70 & $\begin{array}{l}5 \text { palliative } \\
\text { care units }\end{array}$ & $\begin{array}{l}\text { Malignant } \\
\text { primary }\end{array}$ & Variable & $\begin{array}{l}\text { Not } \\
\text { specified }\end{array}$ \\
\hline \multirow{3}{*}{$\begin{array}{l}\text { Focus on } \\
\text { functional } \\
\text { status }\end{array}$} & $\begin{array}{l}\text { Brown et al, } \\
55\end{array}$ & RCTs & 1244 & \begin{tabular}{|l}
8 \\
consecutive \\
NCCTG \\
prospective \\
clinical \\
therapy trials \\
\end{tabular} & $\begin{array}{l}\text { High-grade } \\
\text { primary }\end{array}$ & $\begin{array}{l}\text { At study } \\
\text { entry }\end{array}$ & $\begin{array}{l}\text { Up to } 24 \\
\text { months }\end{array}$ \\
\hline & $\begin{array}{l}\text { Chaichana } \\
\text { et al, }{ }^{56}\end{array}$ & $\begin{array}{l}\text { Chart } \\
\text { review }\end{array}$ & 544 & $\begin{array}{l}\text { Single } \\
\text { inpatient } \\
\text { tertiary-care }\end{array}$ & Glioblastoma & $\begin{array}{l}\text { Prior to } \\
\text { surgery }\end{array}$ & $\begin{array}{l}\text { Not } \\
\text { specified }\end{array}$ \\
\hline & $\begin{array}{l}\text { Bussièr et } \\
\mathrm{al}^{45}\end{array}$ & $\begin{array}{l}\text { Chart } \\
\text { review }\end{array}$ & 143 & \begin{tabular}{|l|}
2 general \\
hospitals \\
\end{tabular} & $\begin{array}{l}\text { High-grade } \\
\text { Gliomas }\end{array}$ & After death & $\begin{array}{l}\text { Up to } 49 \\
\text { months }\end{array}$ \\
\hline \multirow{3}{*}{$\begin{array}{l}\text { Focus on } \\
\text { support } \\
\text { needs }\end{array}$} & $\begin{array}{l}\text { Schubart et } \\
\mathrm{al}^{57}\end{array}$ & Qualitative & $\begin{array}{l}25 \text { family } \\
\text { caregivers }\end{array}$ & $\begin{array}{l}\text { Single site } \\
\text { brain tumor } \\
\text { clinic }+ \\
\text { phone } \\
\text { interviews } \\
\end{array}$ & $\begin{array}{l}\text { Mixed } \\
\text { primary }\end{array}$ & $\begin{array}{l}\text { Variable } \\
\text { (some } \\
\text { Post- } \\
\text { mortem) }\end{array}$ & $\begin{array}{l}\text { Variable } \\
\text { (some } \\
\text { Post- } \\
\text { mortem) }\end{array}$ \\
\hline & Keir et al, ${ }^{58}$ & Qualitative & $\begin{array}{l}60 \\
\text { caregivers }\end{array}$ & $\begin{array}{l}\text { Single site } \\
\text { brain tumor } \\
\text { clinic } \\
\end{array}$ & $\begin{array}{l}\text { Mixed } \\
\text { primary }\end{array}$ & $\begin{array}{l}\text { Follow up } \\
\text { visits to } \\
\text { the clinic }\end{array}$ & $\begin{array}{l}\text { Not } \\
\text { specified }\end{array}$ \\
\hline & $\mathrm{Janda}$ et $\mathrm{a}^{59}$ & $\begin{array}{l}\text { Cross- } \\
\text { sectional } \\
\text { survey }\end{array}$ & $\begin{array}{l}75 \\
\text { patients } \\
70 \\
\text { caregivers }\end{array}$ & $\begin{array}{l}\text { Members } \\
\text { listed on the } \\
\text { database of } \\
\text { The Cancer } \\
\text { Council } \\
\text { Queensland } \\
\text { Brain Tumor } \\
\text { Support } \\
\text { Service }\end{array}$ & $\begin{array}{l}\text { Mixed } \\
\text { primary }\end{array}$ & $\begin{array}{l}\text { Not } \\
\text { specified }\end{array}$ & N/A \\
\hline
\end{tabular}




\section{Objectives}

The primary aim of this study, using administrative data, is to determine, in the province of Quebec, the variability in processes of care of persons dying of primary intracranial tumors

- Where process of care are characterized by:

- Interventions received in last 6 months of life

- Place of death

- Frequency of ICU admissions and ER visits

- Duration of hospitalizations prior to death

- Involvement of main specialists in care (consultation)

- Frequency and type of ambulatory care visits

The secondary aim is to identify determinants of more optimal processes of care of persons dying of primary intracranial tumors and factors that potentially predict the place of death for this group of cancer patients, where determinants are:

- Age, gender and co-morbidities

- Social and material deprivation indexes

- Residence (urban vs. rural)

- Place of follow up (hospital)

- Tumor type 


\title{
Patterns of care at end of life for people with primary intracranial tumors: lessons learned
}

\author{
Abdulrahman Alturki, $\mathrm{MD}^{1,2,3}$, Nancy Mayo $\mathrm{PhD}^{1}$, Kevin Petrecca MD $\mathrm{PhD}^{2}$, \\ Susan C. Scott, $\mathrm{MSc}^{1}$, Lyne Nadeau MSc ${ }^{1}$, Bruno Gagnon MD MSc ${ }^{1}$
}

1 Department of Epidemiology and Biostatistics, Division of Clinical

Epidemiology, Royal Victoria Hospital, Montreal, Quebec, Canada

2 Department of Neurosurgery, the Montreal Neurological Institute and Hospital, Montreal, Quebec, Canada

3 Department of Neurosurgery, the National Neurosciences Institute, King Fahad Medical City, Riyadh, Saudi Arabia 


\section{Introduction}

In Canada, from 2000 to 2009, deaths caused by major cardiovascular diseases have declined, while deaths caused by cancer have increased such that since 2007, cancer deaths are more numerous than cardiovascular deaths. ${ }^{29}$

Advances in technology have made earlier diagnosis of cancer possible, management is increasingly multimodal and multidisciplinary, and the population is aging, especially in the high-income societies. These secular changes have increased the complexity of care and the diversity of the population seeking care; this is even more so, regarding the care of the dying.

One of the challenges facing practitioners managing care and outcomes of persons with primary intracranial tumors is balancing reducing tumor burden while maintaining an acceptable quality of life, even until the end of life.

In spite of aggressive multimodality treatment with surgery, radiotherapy, and chemotherapy, the prognosis of patients with primary or metastatic intracranial tumors remains poorer than that of other tumor sites, especially for those affected by malignant tumors. While advances are being made in treatment, the health care team looking after patients with intracranial tumors also have the important role of providing effective and adequate supportive care for symptoms and complications arising from the tumor and its treatment. ${ }^{31}$

People with intracranial tumors have the same "general tumor symptoms" as people with other types of tumors, but they also experience consequences of focal 
neurological deficits, such as motor deficit, aphasia, or visual field defects. Because of these sequelae, the functional impact of intracranial tumors is much more widespread than that of other cancers. In the last stage of disease, patients with intracranial tumors may become functionally dependent due to tumor progression or treatment side effects, necessitating an even greater need for palliative and supportive care. ${ }^{33}$

Improving end of life experience is a major challenge to the health care system. Deaths that are reasonably free of discomfort, in accordance with patients' wishes, and within acceptable professional and ethical standards, are considered highquality deaths ${ }^{48}$. Promoting quality of life and reducing the burden of care to the patient are pivotal to the philosophy of end of life care 5 . How much has this philosophy influenced the care received by patients with intracranial tumors?

Prospective studies, while optimal for addressing questions about end of life care are costly and difficult to execute. A retrospective approach is an efficient way to monitor end of life care across jurisdictions, demographic groups and time periods. ${ }^{6}$

The clinical information available in administrative databases can provide relevant answers to questions about processes of care at end of life; such studies are feasible, and allow the study of the whole population at a reasonable cost. ${ }^{5,9}$

A limitation is that not all the elements characterizing the care received by the patient are directly documented in administrative databases. However, certain 
elements of care that reflect provision of palliative care are available and can be used as indicators of the quality of end of life cancer care and could be extracted from administrative databases. One feature of high quality end of life care is the possibility of a patient remaining at home or other place that fosters dying in relative comfort and dignity. On the contrary, frequent emergency department visits or admissions to hospital near the end of life are considered indicators of less than optimal end of life cancer care.

The primary aim of this study is to determine, using administrative data in the province of Quebec, the variability in processes of care of persons dying of primary intracranial tumors, where processes of care are characterized by:

- Interventions received in last 6 months of life

- Place of death

- Frequency of ICU admissions and ER visits

- Duration of hospitalizations prior to death

- Involvement of main specialists in care (consultation)

- Frequency and type of ambulatory care visits

The secondary aim is to identify determinants of more optimal processes of care of persons dying of primary intracranial tumors and factors that potentially predict the place of death for this group of cancer patients, where determinants are:

- Age, gender and co-morbidities

- Social and material deprivation indexes 
- Residence (urban vs. rural)

- $\quad$ Place of follow up (hospital)

- Tumor type 


\section{Methods}

\section{Data Sources}

In Canada, coverage for health care services provided by physicians and hospitals is universal; prescription medication coverage varies by province. Each province maintains, for reimbursement purposes, its own set of health databases covering hospital services, fee-for-service billings for visits, tests and procedures, and prescriptions filled. For the purposes of identifying services provided at end of life for people with intracranial tumors, linkage between the death registry, the hospital discharge database (MedEcho) and the billing databases maintained by Régie de l'Assurance Maladie du Québec (RAMQ) was carried out. The death registry lists principle cause of death. MedEcho contains coded information of all hospital separations. There are data fields for the Medicare number of the subject (NAM), final diagnoses and 14 secondary diagnoses, topography codes serving as specific identification of cancer diagnosis and sites of metastases, dates of admission and discharge, type of bed (acute care, chronic care, or palliative care) during hospitalization, status at discharge (alive or dead), discharge destination (e.g., home, other institution), age, gender, regional indicators, and procedures. Type of institution (acute care vs. chronic care) is also coded.

The RAMQ databases contain, among other things, the NAM (identical to the NAM in MedEcho); a beneficiary file containing all fee for services received (code of act), site of act (e.g., at home, in chronic care institution, emergency department, out patient clinic, acute care institution), specialty of physician 
performing the act (e.g., identification code of the physician, date of act); and a physician file containing some information about the physician (age, sex, and licensing information). The linkage of the databases is done at the ministry level through the NAM, and the merged file is provided with an identification number that is denominalized to respect confidentiality.

The validity and completeness of the RAMQ database have been verified and shown to be high..$^{67,68}$ The MedEcho database was also used to capture additional details concerning the treatments received.

\section{Design}

A death-backwards cohort was assembled using historical data compiled from the three health administration databases for the years 2003 to 2006, inclusive. The study time interval was selected to reflect cancer evolution before death. In

general, cancer patients experience a marked decline in their physical function in their last 6 months of life. ${ }^{13}$

\section{Procedures}

Figure 4-1 shows how records for inclusion in the primary intracranial tumor end of life study were chosen. From the two data sources on hand, the death registry (box a: $n=67655$ ) and hospitalization database (box b: $n=83566$ ), an algorithm using ICD codes was applied (box c) to extract those records of people diagnosed with a single intracranial tumor (box d: $n=1922$ and box e: $n=468$ ). From the hospitalization group (box e), we included only those deaths that could be 
attributed to the disease or treatment (box f). To the records arising from both data sources, histology codes were consulted to identify those with a proven primary intracranial tumor thereby eliminating those with a single intracranial metastatic lesion (box g) yielding 1607 records from death certificates (box h) and 106 records from hospitalization data (box i). The records in box i were further scrutinized to eliminate people whose death may have originated from causes not related to the disease or its treatment (box k: n=90) and may have "died with" their tumor. The final death-backwards cohort comprised 1,623 people (box j). Appendix 2 shows the ICD-9 and 10 codes for selecting records for single intracranial tumors (box c); appendix 3 provides the histology codes (box g). Appendix 4 provides the list of diagnostic codes encountered in end of life situations for intracranial tumors which would satisfy the condition for dying of the disease or its treatment including septic complications, thrombosis, gastrointestinal bleed, delirium, and ill-defied medical conditions at the end of life. Diagnoses excluded from this list were related to chronic progressive diseases that by themselves lead to death such as COPD, congestive heart failure, amyotrophic lateral sclerosis, Parkinson's disease, dementia, etc. People with final diagnoses not related to pathologies listed in appendix 4 were considered to have died with primary intracranial tumors.

\section{Measures}

Two outcomes indicative of quality of end of life care were care burden and place of death. The care burden outcome was created to reflect the impact of care 
processes on the patient ${ }^{69}$ rather than that of the health care system. An estimate of care burden for each subject was created using characteristics of care during the last 6 months of life, based on: number of intensive care unit (ICU) admissions (03), emergency room (ER) visits (0-7), duration of hospital stay in months (0-6), neurosurgical interventions received (0-3), radiotherapy received (0-1), oncologist consultation (0-1), neurosurgeon consultation (0-1). The care burden was an ordinal variable ranging from 0 (low burden) to 13 (high burden). (Appendix 5)

Place of death was an ordinal variable ordered from worst $(E R=5)$ to best $($ Home $=0)$, with dying in acute care bed (4), chronic care (3), palliative care (2), and hospice (1), as intermediate categories.

The potential predictors were: age, gender, residence, comorbidity, social and material deprivation indices and tumor type. A comorbidity score was created for each subject using the Romano-Roos Dartmouth-Manitoba modification of the Charlson comorbidity index to include all available diagnostic information ${ }^{70}$. Social and material deprivation indices were assessed by using the method developed in Canada, using Canadian census data, by Pampalon et $\mathrm{al}^{71}$. In brief, six indicators were taken into account to construct the index: the proportion of people aged 15 years and older with no high school diploma, the employment/ population ratio of people aged 15 years and older, the average income of people aged 15 years and older, the proportion of individuals aged 15 years and older living alone, the proportion of individuals aged 15 years an older who are separated, divorced or widowed, the proportion of single-parent families. Quintile 
1 represents the most privileged population and quintile 5, the least. For this study, we covered the 5 years preceding death (brain cancer-related diagnoses were excluded from the comorbidity index). Tumor type was identified from the histology codes and was dichotomized into either grade 4 astrocytoma (GBM) or not.

The hospital of origin and year of death were also identified in order to account for these in the analysis as potential confounders for both place of death and the level of care burden. Hospital was assigned based on neurosurgical interventions during the 5 years prior to death; if there was more than one, the last intervention was chosen. In total, 1155 subjects were linked to11 hospitals using neurosurgical information; 310 were linked to these 11 hospitals using other data (such as ICU admissions); and the remaining 159 people were classified as receiving care at other hospitals.

\section{$\underline{\text { Statistical Analysis }}$}

The analysis related two ordinal outcomes, level of care burden, and place of death with key explanatory variables using ordinal regression model. ${ }^{72}$ The proportional odds model was chosen to estimate the cumulative proportional odds ratio (CPOR) for outcome (with $\mathrm{k}$ categories) as a function of predictors. The predictors were scored to reflect the odds of increased care burden or unfavorable

place of death with respect to categories of predictors. The CPOR is interpreted as the odds of a poorer outcome for one level of a predictor relative to the odds for another level of the predictor, regardless of how "poorer" outcome is defined. 
Odds ratios for k-1 ordinal outcome categories are produced. A $\chi^{2}$ test of homogeneity of the CPOR across levels of the outcomes was carried out, however, as this test is known to be overly sensitive to sparse cells ${ }^{72}$, the consistency of the odds ratios across cut points was verified by inspection.

For each level of predictor a reference category was defined based on convention or distribution.

All predictors were dummy coded. For place of death, two models were considered, excluding and including care burden as a predictor. All analyses were conducted using SAS ${ }^{\circledR} 9.2$ statistical software package. 


\section{$\underline{\text { Results }}$}

\section{Demographic characteristics}

Between 2003 and 2006, 1623 people died from primary intracranial tumors or their treatment side effects. Table 4-1 provides key characteristics of the 1065 people $(65.6 \%)$ who were diagnosed with WHO grade 4 astrocytoma (Glioblastoma multiforme or GBM) and the remaining diagnosed with other tumor types. Of note, $70 \%$ of the sample was between 50 and 79 years of age, $57.4 \%$ were men, the majority had an urban address $(81 \%)$ based on Canadian postal code Forward Sortation Area (FSA) and 64.9\% had a Charlson Comorbidity Index of 3 and above. The social and material deprivation indices showed the expected distribution by quintile. The distribution of the sample across hospital of care ranged from $2.9 \%$ to $19.6 \%$. Place of death, distributed from least to most frequent, ER (1.1\%), home (9.8\%), hospice (11.9), chronic care (16.9\%), PCU (29.6\%), acute care (31\%).

Table 4-2 shows distribution of the number of people receiving each type of health care encounters over the last six months of life and table 4-3 shows the distribution according to place of death. For ICU admissions, 1143 patients (70.4\%) had none, 385 (23.7\%) had one, and 95 (5.8)\% had two or more. More frequent admissions are noted for people died in an acute care unite and ER. 106 patients had three or more ER visits in the 6 months prior to death; more visits for people died in ER or acute care. More than $90 \%$ of the population spent one month or more in the hospital over the six months period, more time in hospital is 
observed for people who died in PCU and acute care bed (none stayed less than 1 month). Of the people who died in acute care, $78.3 \%$ stayed more than a week in the last admission leading to death.

Patients receiving intracranial tumor targeted treatments during this period represented $15.6 \%$ and $28 \%$ of the total population for surgery and radiotherapy respectively. These treatments were more common for people who died in ER, PCU and in an acute care bed. Additionally, $13.4 \%$ of the population had one or more consultations with a neurosurgeon, $14.8 \%$ with an oncologist in the last 6 months of life, noted more for people died in an acute care unite and ER. 11.1\% and $25.5 \%$ had a consultation with general practitioners and palliative care physicians, respectively. $19 \%$ of the population had at least one home visit by a physician during this period, more for people died at home and hospice. At the community level (outpatient clinic visits, emergency clinics, CLSC) more than $60 \%$ of the patients had at least one visit by a specialist or a general practitioner, more common for people who died in ER and at home (specialist) or ER and hospice (general practitioner).

Factors modifying the level of care burden and place of death

The overall estimate of level of care burden for each subject ranged from 0 to 13 (mean 3.65 and SD 2.3) (appendix 5). The five highest scores (9-13) were grouped together as they contained only small numbers of subjects, leaving ten ordinal levels of care burden (0-9). 
Table 4-4 shows the cumulative proportional odds ratio (CPOR) estimating level of care burden (model 1) and place of death accounting for level of care burden in (model 2) across different variables. Age group (70-79 years), Charlson comorbidity index 2,4 , and $\geq 5$, and tumor type (GBM) affected the level of care burden, with CPOR and 95\% CI of 1.34 (1.03-1.75), 1.43 (1.14-1.8), 2.02 (1.3$3.13), 1.82(1.36-2.44)$ and $1.44(1.19-1.74)$ respectively, indicating an increase in the relative odds of care burden.

Level of care burden and age over 70 years had a higher odds to die in a treatment intensive place of death on the ordinal scale (e.g. ER or acute care), with CPOR and $95 \% \mathrm{CI}$ of 1.15 (1.11- 1.2), $1.52(1.16-2)$ and 1.89 (1.3- 2.74) respectively. Patients diagnosed with GBM had a lower odds to die in a treatment intensive place of death on the ordinal scale, with CPOR and 95\% CI of 0.74 (0.6-0.9).

\section{DISCUSSION}

Using administrative data, this study demonstrated that at the population level, there was considerable variability in the processes of care experienced by persons dying of primary intracranial tumors. One major finding in this study was the low rate of home deaths. A $9.8 \%$ home death rate represents one of the lowest documented in the literature and less then the expected average (18.8\%) in cancer studies and is approached only by a study from Quebec and a study from Japan with a reported home death rate of $6.9 \%$ and $8.2 \%$ respectively. ${ }^{5,73}$ In brain cancer studies, accounting for different methods in data collection ,this study represents the lowest reported rate..$^{52,74,75}$ 
Several possible explanations for this low rate of home death could be extracted from the data: age ( $>60 \%$ of subjects are above 60 years), a high proportion of subjects needing to go the emergency department repeatedly to receive care, prolonged hospital inpatient duration, low involvement of general practitioners and few home visits, as most of these factors have been associated with a lower probability of dying at home..$^{73,76-79}$ While it was not possible to document other factors such as presence of family caregivers, or subject's wishes, a study by Pritchard et $\mathrm{al}^{80}$ showed that the most important factor contributing to a low rate of home death is the accessibility and utilization of acute care beds. In the province of Quebec, the rate was 4.4 hospital beds per 1,000 inhabitants (2002), the definition of high accessibility is a rate of hospital beds of greater than 3.3 beds per 1,000 beneficiaries. ${ }^{81}$ Thus, in this province the low home death rate is compatible with this high number of beds per population. Another potential explanation for the variability in place of death across various studies is the different national health systems.

Consultation with specialists in palliative care was low $(25.5 \%)$. This low rate of palliative care consultation, coupled with a comparably low rate of death in a palliative care beds (Hospice 11.9\% and PCU 29.6\%) suggests, the will to refer, but still a scarcity of palliative care specialists working in cancer centers and acute care hospitals. ${ }^{5}$

Taken together, all these findings suggest that, for the period from 2003 to 2006, efforts were made to have better access to resources for end of life care for 
subjects dying of primary intracranial tumors. More access needs to be facilitated to some of these recourses like home visits by physicians, general practitioner early involvement in care and to keep and even improve others like visits in the community by different physicians (specialist or general practitioners).

It should be emphasized that the level of care burden is simply a numeric approach to summarize processes of care that have been indicated in the literature as being poor end of life quality care (frequent emergency room and ICU admissions, high number of hospital days near the end of life. $)^{9}$ Or cure oriented processes (interventions, specialists involvement near the end of life) ${ }^{82}$. It was constructed for the purposes of facilitating statistical analysis and to assess factors that potentially affect it, it was not intended as a measure of care burden, rather a statistical indicator of this construct. Others are working on quantifying and qualifying burden of treatment for different chronic conditions ${ }^{69,83}$ and more research needs to be done on this construct as it relates to cancer in general and to end of life.

The results of the analyses on factors contributing to the level of care burden provide evidence that: older age, greater comorbidities, and the type of tumor (GBM) were associated with higher burden. These factors have been also found to affect the functional status of the patient and subsequently increase the likelihood of being dependent near the end of life with the expected increase in care burden (more visits to the ER, increasing time spent in hospital, etc.). ${ }^{45} 50$

Other studies have also found that terminal cancer patients who died in a hospital 
spent more of their final life in the hospital than those who died at home. ${ }^{84-86}$ Cure oriented processes such as the performance of surgical procedures or administration of other treatments and diagnostic evaluation were likely to be associated with death at places other than home. ${ }^{87}$

Contradictory findings were documented in the published studies of adult cancer patients regarding age as the influencing factor on place of death. Some studies concluded that the probability of dying in the hospital diminished with increasing age, ${ }^{88,89}$ others found that the probability of dying at home diminished with age..$^{90}$ Costantini and colleagues ${ }^{91}$ concluded that the proportion of home deaths significantly increased with increasing age at death. To add to the controversy, many studies demonstrated no significant difference in the average age between home-death and hospital-death groups. ${ }^{87,92}$ Age is likely a proxy variable for a number of other unmeasured factors such as social support and health-care network.

Type of cancer is likely to influence the place of death through symptoms, complication, and functional status; however, the relationship of specific diagnosis and place of death is not conclusive ${ }^{87,90-92}$. Hematological malignancies were the only diagnosis that had been repeatedly shown to predict hospital death. Patients with hematological malignancies often die from complications, such as infection, that tend to precipitate readmission to the hospital. ${ }^{87,90-92}$ Many theories have been proposed to explain the lack of congruence of relationships between diagnosis and place of death. ${ }^{11,93}$ A longer prognosis allows the family to organize 
the care of these patients at home. Slow progression of disease would allow progressive mental adjustment and the development of the necessary skills to take care of patients at home. In contrast, the family may lack the economic, psychosocial, and emotional resources to care for the patient with slow progressing cancers at home for a prolonged period of time, resulting in terminal hospitalization. Other theories suggest that the likelihood of death at home was positively associated with longer periods of survival after diagnosis and that patients with a shorter survival time were more likely to die in a hospital.

Limitations of using administrative databases have been highlighted elsewhere ${ }^{94-}$ ${ }^{96}$. For this study, and to an extent other end of life care studies, the databases will not capture some of the information considered important by patients, families and care providers, such as psychosocial care, multidisciplinary treatment, pain and symptom management, spiritual well-being and advanced directives. Nevertheless, this study opens an avenue that is convenient, generalizable, and efficient for evaluating and implementing performance indicators related to end of life care in this patients population.

This study was successful, using existing administrative databases, in documenting important indicators of level of care burden, services provided at the end of life and there effect on place of death for patients died from primary intracranial tumors. An advantage of this type of study is that it is populationbased and that the data are robust: physicians are paid on the basis of services rendered, and completeness and accuracy of reporting have monetary incentives 
attached.

Similar methodologies could be used to evaluate other health care delivery systems across providers, geographic areas, demographic groups, and time periods, to help promote better health care policies for the dying, and to monitor changes over time, especially after the introduction of these new health service policies. 
Death certificate main cause of death is cancer, $\mathrm{n}=67655$

(a)

Coding algorithm for single intracranial tumors (ICD $9 \&$

10) (Appendix 2)
Using hospitalization MedEcho dataset, $\mathrm{n}=83556$

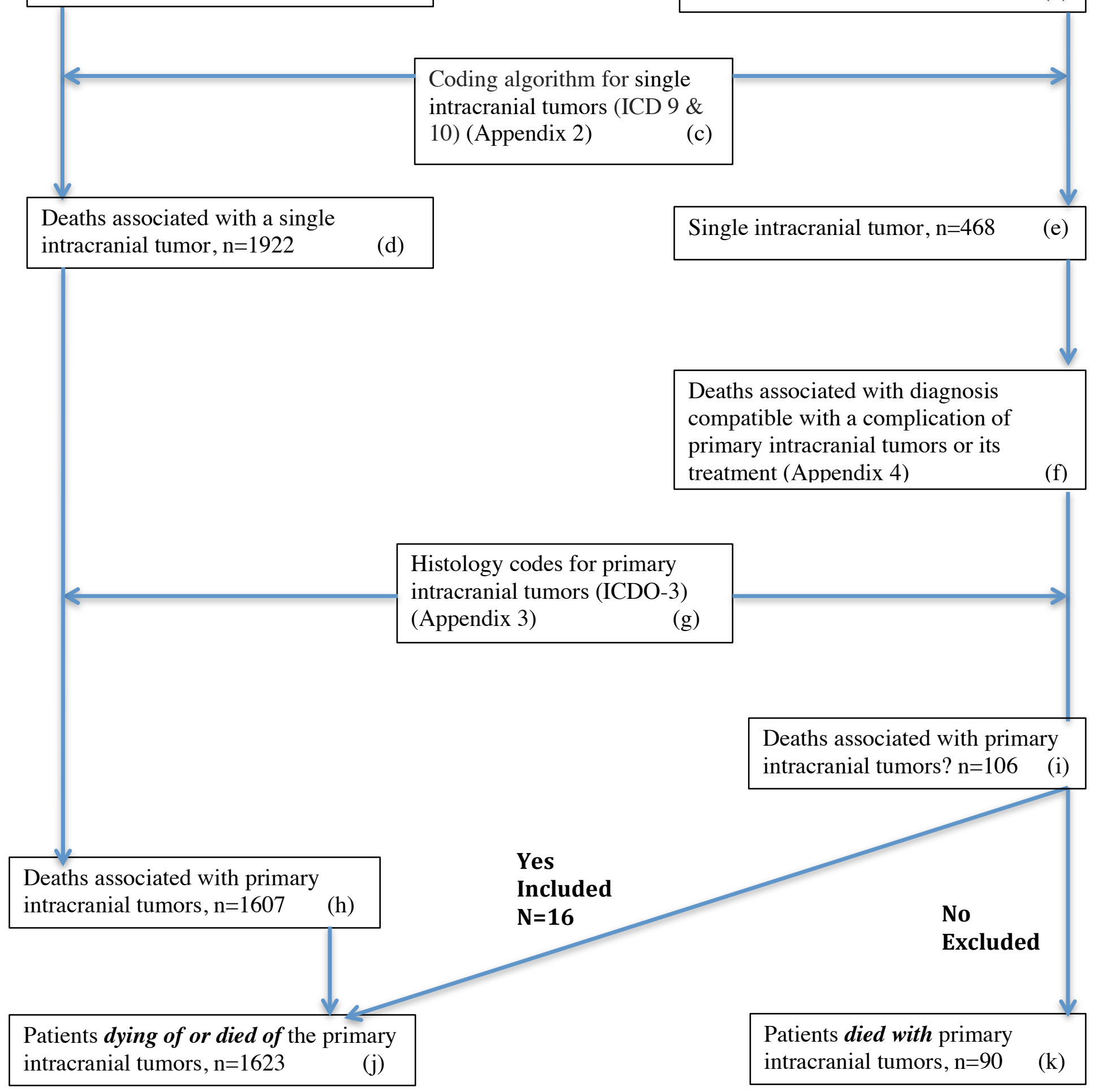

Figure 4-1: Identification of records for inclusion in the primary intracranial tumor end of life study 
Table 4-1: Characteristics of the 1623 decedents from primary intracranial tumors

\begin{tabular}{|c|c|c|c|}
\hline \multirow{2}{*}{ Variable } & \multicolumn{2}{|c|}{ Tumor type ${ }^{1}$} & \multirow{2}{*}{ All $(n=1623)$} \\
\hline & GBM (n=1065) & Others $(n=558)^{2}$ & \\
\hline \multicolumn{4}{|c|}{ Age category (years) } \\
\hline$\leq 39$ & $30(2.8)$ & $77(13.8)$ & $107(6.6)$ \\
\hline $40-49$ & $113(10.6)$ & $102(18.3)$ & $215(13.3)$ \\
\hline $50-59$ & $212(19.9)$ & $103(18.5)$ & $315(19.4)$ \\
\hline $60-69$ & $318(29.9)$ & $100(17.9)$ & $418(25.7)$ \\
\hline $70-79$ & $273(25.6)$ & $129(23.1)$ & $402(24.8)$ \\
\hline$\geq 80$ & $119(11.2)$ & $47(8.4)$ & $166(10.2)$ \\
\hline \multicolumn{4}{|l|}{ Gender } \\
\hline Men & $624(58.6)$ & $307(55)$ & $931(57.4)$ \\
\hline Women & $441(41.4)$ & $251(45)$ & $692(42.6)$ \\
\hline \multicolumn{4}{|l|}{ Year of death } \\
\hline 2003 & $232(21.8)$ & $141(25.3)$ & $373(23)$ \\
\hline 2004 & $262(24.6)$ & $139(24.9)$ & $401(24.7)$ \\
\hline 2005 & $251(23.6)$ & $129(23.1)$ & $380(23.4)$ \\
\hline 2006 & $320(30)$ & $149(26.7)$ & $469(28.9)$ \\
\hline \multicolumn{4}{|l|}{ Residence $^{3}$} \\
\hline Urban & $863(81)$ & $458(82)$ & $1321(81)$ \\
\hline Rural & 202 (19) & $100(18)$ & $302(19)$ \\
\hline \multicolumn{4}{|c|}{ Charlson Comorbidity Index 4} \\
\hline$\leq 1$ & $1(0.1)$ & $7(1.3)$ & $8(0.5)$ \\
\hline 2 & $383(36)$ & $179(32.1)$ & $562(34.6)$ \\
\hline 3 & $216(20.3)$ & $94(16.8)$ & $310(19.1)$ \\
\hline 4 & $198(18.6)$ & $122(21.9)$ & $320(19.7)$ \\
\hline$\geq 5$ & $267(25)$ & $156(27.9)$ & $423(26.1)$ \\
\hline \multicolumn{4}{|c|}{ Social deprivation index (Quintile) } \\
\hline 1 & $196(18.4)$ & $87(15.6)$ & $283(17.4)$ \\
\hline 2 & $205(19.3)$ & $128(22.9)$ & $333(20.5)$ \\
\hline 3 & $211(19.8)$ & $108(19.4)$ & $319(19.7)$ \\
\hline 4 & $207(19.4)$ & $102(18.3)$ & $309(19.1)$ \\
\hline 5 & $208(19.5)$ & $104(18.6)$ & $312(19.2)$ \\
\hline Missing & $38(3.6)$ & $29(5.2)$ & $67(4.1)$ \\
\hline \multicolumn{4}{|c|}{ Material deprivation index (Quintile) } \\
\hline 1 & $217(20.4)$ & $86(15.4)$ & 303 (18.7) \\
\hline 2 & $206(19.3)$ & $91(16.3)$ & $297(18.3)$ \\
\hline 3 & $232(21.8)$ & 104 (18.7) & $336(20.7)$ \\
\hline 4 & $183(17.2)$ & $123(22)$ & $306(18.9)$ \\
\hline 5 & 189 (17.7) & $125(22.4)$ & $314(19.3)$ \\
\hline Missing & $38(3.6)$ & $29(5.2)$ & $67(4.1)$ \\
\hline \multicolumn{4}{|l|}{ Hospital } \\
\hline 1 & $80(7.5)$ & $40(7.2)$ & $120(7.4)$ \\
\hline 2 & $31(2.9)$ & $19(3.4)$ & $50(3)$ \\
\hline 3 & $33(3.1)$ & $24(4.3)$ & $57(3.5)$ \\
\hline 4 & 205 (19.2) & $73(13.1)$ & $278(17.2)$ \\
\hline
\end{tabular}




$\begin{array}{llll}5 & 74(6.9) & 26(4.6) & 100(6.2) \\ 6 & 87(8.2) & 47(8.4) & 134(8.2) \\ 7 & 52(4.9) & 19(3.4) & 71(4.4) \\ 8 & 184(17.3) & 135(24.2) & 319(19.6) \\ 9 & 50(4.7) & 44(7.9) & 94(5.8) \\ 10 & 31(2.9) & 16(2.8) & 47(2.9) \\ 11 & 135(12.7) & 59(10.6) & 194(12) \\ \text { Others } & 103(9.7) & 56(10) & 159(9.8) \\ \text { Place of death } & 163(15.3) & 106(19) & 269(16.6) \\ \text { Chronic care } & 10(0.9) & 8(1.4) & 18(1.1) \\ \text { Emergency room } & 65(11.6) & 193(11.9) \\ \text { Home } & 94(8.8) & 52(9.3) & 481(29.6) \\ \text { Hospice } & 141(13.2) & 145(25.9) & 503(31) \\ \text { PCU } & 336(31.6) & 182(32.6) & \\ \text { Acute care } & 321(30.1) & & \\ \text { 1-Based on the last histological diagnosis (ICDO-3 codes) recorded during the last admission } \\ \text { leading to death }\end{array}$


Table 4-2: Distribution of the number of people receiving each type of health care encounters over the last six months of life

\begin{tabular}{|c|c|}
\hline $\mathbf{N}$ of health care encounters & Number of subjects \\
\hline \multicolumn{2}{|l|}{ ICU admissions } \\
\hline 0 & $1143(70.4)$ \\
\hline 1 & $385(23.7)$ \\
\hline 2 & $76(4.7)$ \\
\hline 3 & $19(1.2)$ \\
\hline \multicolumn{2}{|l|}{ ER visits ${ }^{1}$} \\
\hline 0 & $909(56)$ \\
\hline 1 & $429(26.4)$ \\
\hline 2 & $179(11.1)$ \\
\hline 3 & $70(4.3)$ \\
\hline 4 & $18(1.1)$ \\
\hline 5 & $15(0.9)$ \\
\hline 7 & $3(0.2)$ \\
\hline \multicolumn{2}{|l|}{ Time spent in hospital (months) } \\
\hline 0 & $156(9.6)$ \\
\hline 1 & $649(40)$ \\
\hline 2 & $436(26.9)$ \\
\hline 3 & $213(13.1)$ \\
\hline 4 & $80(4.9)$ \\
\hline 5 & $48(3)$ \\
\hline 6 & $41(2.5)$ \\
\hline \multicolumn{2}{|c|}{ Duration of last admission leading to death in acute care. } \\
\hline$<7$ days & $109(21.7)$ \\
\hline$\geq 7$ days & $394(78.3)$ \\
\hline \multicolumn{2}{|c|}{ Received neurosurgical intervention } \\
\hline 0 & $1370(84.4)$ \\
\hline 1 & $235(14.5)$ \\
\hline 2 & $15(0.9)$ \\
\hline 3 & $3(0.2)$ \\
\hline \multicolumn{2}{|l|}{ Received radiotherapy } \\
\hline No & $1168(72)$ \\
\hline Yes & $455(28)$ \\
\hline \multicolumn{2}{|l|}{ Neurosurgeon consulted $^{2}$} \\
\hline No & 1406 (86.6) \\
\hline Yes & $217(13.4)$ \\
\hline \multicolumn{2}{|l|}{ Oncologist consulted $^{2}$} \\
\hline No & $1383(85.2)$ \\
\hline Yes & $240(14.8)$ \\
\hline \multicolumn{2}{|c|}{ General practitioner consulted ${ }^{2}$} \\
\hline No & $1443(88.9)$ \\
\hline Yes & $180(11.1)$ \\
\hline Palliative care physician con & \\
\hline
\end{tabular}




\begin{tabular}{lc}
\hline No & $1210(74.5)$ \\
Yes & $413(25.5)$ \\
$\geq 1$ home visit by a physician & $1328(81.8)$ \\
No & $295(18.2)$ \\
Yes & $637(39.2)$ \\
$\geq 1$ visit in the community by a specialist & \\
No & $986(60.8)$ \\
Yes & $537(33)$ \\
$\geq 1$ visit in the community by a general practitioner \\
No & $1086(67)$ \\
Yes & \\
\hline
\end{tabular}

1- not including the ER visit leading to the last admission leading to death

2- consults done during admissions (extracted from MedEcho). More than one consult per subject was accounted as one

3- Includes Neurosurgeons, Neurologists, Oncologist, and Radiation oncologists 
Table 3: Distribution of the number of people receiving each type of health care encounters over the last six months of life according to place of death*

\begin{tabular}{|c|c|c|c|c|c|c|}
\hline \multirow{4}{*}{$\begin{array}{l}\mathrm{N} \text { of health } \\
\text { care encounters } \\
\text { (overall places } \\
\text { of death) }\end{array}$} & \multicolumn{6}{|c|}{ Place of death } \\
\hline & $\begin{array}{l}\text { Chronic } \\
\text { care }\end{array}$ & $\begin{array}{l}\text { Emergency } \\
\text { room }\end{array}$ & Home & Hospice & PCU & $\begin{array}{l}\text { Acute care } \\
\text { unite }\end{array}$ \\
\hline & $n=269$ & $\mathrm{n}=18$ & $n=159$ & $n=193$ & $n=481$ & $\mathrm{n}=\mathbf{5 0 3}$ \\
\hline & $(16.6 \%)$ & $(1.1 \%)$ & $(9.8 \%)$ & $(11.9 \%)$ & $(29.6 \%)$ & $(31 \%)$ \\
\hline \multicolumn{7}{|l|}{ ICU admissions } \\
\hline $0(n=1143)$ & $227(84.4)$ & $10(55.6)$ & $124(78)$ & $145(75.1)$ & $360(74.8)$ & $277(55.1)$ \\
\hline $1(\mathrm{n}=385)$ & $33(12.3)$ & $6(33.3)$ & $28(17.6)$ & $41(21.2)$ & $103(21.4)$ & $174(34.6)$ \\
\hline $2(n=76)$ & $8(3)$ & $2(11.1)$ & $4(2.5)$ & $6(3.1)$ & $14(2.9)$ & $42(8.3)$ \\
\hline $3(n=19)$ & $1(0.3)$ & $0(0)$ & $3(1.9)$ & $1(0.5)$ & $4(0.8)$ & $10(2)$ \\
\hline \multicolumn{7}{|l|}{ ER visits ${ }^{1}$} \\
\hline $0(n=909)$ & $192(71.4)$ & $0(0)$ & $75(47.2)$ & $107(55.4)$ & $266(55.3)$ & $269(53.5)$ \\
\hline $1(n=429)$ & $49(18.2)$ & $8(44.4)$ & $44(27.7)$ & $54(28)$ & $133(27.7)$ & $141(28)$ \\
\hline $2(n=179)$ & $17(6.3)$ & $4(22.2)$ & $27(17)$ & $17(8.8)$ & $58(12.1)$ & $56(11.1)$ \\
\hline $3(n=70)$ & $8(3)$ & $2(11.1)$ & $5(3.1)$ & $11(5.7)$ & $14(2.9)$ & $30(6)$ \\
\hline $4(n=18)$ & $2(0.7)$ & $2(11.1)$ & $2(1.3)$ & $3(1.6)$ & $5(1)$ & $4(0.8)$ \\
\hline $5(n=15)$ & $1(0.3)$ & $1(5.6)$ & $5(3.1)$ & $1(0.5)$ & $5(1)$ & $2(0.4)$ \\
\hline $7(\mathrm{n}=3)$ & $0(0)$ & $1(5.6)$ & $1(0.6)$ & $0(0)$ & $0(0)$ & $1(0.2)$ \\
\hline \multicolumn{7}{|c|}{ Time spent in hospital (months) } \\
\hline $0(\mathrm{n}=156)$ & $73(27.1)$ & $5(27.8)$ & $40(25.2)$ & $38(19.7)$ & $0(0)$ & $0(0)$ \\
\hline $1(\mathrm{n}=649)$ & $69(25.6)$ & $10(55.6)$ & $80(50.3)$ & $87(45.1)$ & $185(38.5)$ & $218(43.3)$ \\
\hline $2(n=436)$ & $69(25.6)$ & $2(11.1)$ & $28(17.6)$ & $42(21.8)$ & $148(30.8)$ & $147(29.2)$ \\
\hline $3(n=213)$ & $33(12.3)$ & $1(5.6)$ & $8(5)$ & $19(9.8)$ & $79(16.4)$ & $73(14.5)$ \\
\hline $4(n=80)$ & $14(5.2)$ & $0(0)$ & $1(0.6)$ & $5(2.6)$ & $32(6.7)$ & $28(5.6)$ \\
\hline $5(\mathrm{n}=48)$ & $8(3)$ & $0(0)$ & $1(0.6)$ & $2(1)$ & $17(3.5)$ & $20(4)$ \\
\hline $6(n=41)$ & $3(1.1)$ & $0(0)$ & $1(0.6)$ & $0(0)$ & $20(4.2)$ & $17(3.4)$ \\
\hline \multicolumn{7}{|c|}{ Duration of last admission leading to death in acute care } \\
\hline$<7$ days & - & - & - & - & - & $109(21.7)$ \\
\hline$\geq 7$ days & - & - & - & - & - & $394(78.3)$ \\
\hline \multicolumn{7}{|c|}{ Received neurosurgical intervention } \\
\hline $0(n=1370)$ & $246(91.4)$ & $12(66.7)$ & $142(89.3)$ & $169(87.6)$ & $414(41.6)$ & $387(77)$ \\
\hline $1(n=235)$ & $23(8.6)$ & $5(27.8)$ & $14(8.8)$ & $22(11.4)$ & $63(13.1)$ & $108(21.5)$ \\
\hline $2(n=15)$ & $0(0)$ & $1(5.6)$ & $3(1.9)$ & $1(0.5)$ & $3(0.6)$ & $7(1.4)$ \\
\hline $3(n=3)$ & $0(0)$ & $0(0)$ & $0(0)$ & $1(0.5)$ & $1(0.2)$ & $1(0.2)$ \\
\hline \multicolumn{7}{|c|}{ Received radiotherapy } \\
\hline No $(n=1168)$ & $215(80)$ & $9(50)$ & $120(75.5)$ & $153(79.3)$ & $338(70.3)$ & $333(66.2)$ \\
\hline Yes $(n=455)$ & $54(20)$ & $9(50)$ & $39(24.5)$ & $40(20.7)$ & $143(29.7)$ & $170(33.8)$ \\
\hline \multicolumn{7}{|c|}{ Neurosurgeon consulted ${ }^{2}$} \\
\hline No $(n=1406)$ & $243(90.3)$ & $17(94.4)$ & $146(91.8)$ & 173(89.6) & $407(84.6)$ & $420(83.5)$ \\
\hline Yes $(n=217)$ & $26(9.7)$ & $1(5.6)$ & $13(8.2)$ & $20(10.4)$ & $74(15.4)$ & $83(16.5)$ \\
\hline \multicolumn{7}{|c|}{ Oncologist consulted 2} \\
\hline No $(n=1383)$ & $233(86.6)$ & $16(88.9)$ & $138(86.8)$ & $166(86)$ & $412(85.7)$ & $418(83.1)$ \\
\hline Yes $(n=240)$ & $36(13.4)$ & $2(11.1)$ & $21(13.2)$ & $27(14)$ & $69(14.3)$ & $85(16.9)$ \\
\hline
\end{tabular}




\begin{tabular}{|c|c|c|c|c|c|c|}
\hline \multicolumn{7}{|c|}{ General practitioner consulted ${ }^{2}$} \\
\hline No $(n=1443)$ & $236(87.7)$ & $18(100)$ & $150(94.3)$ & $165(85.5)$ & 423(87.9) & $451(89.7)$ \\
\hline Yes $(n=180)$ & $33(12.3)$ & $0(0)$ & $9(5.7)$ & $28(14.5)$ & $58(12.1)$ & $52(10.3)$ \\
\hline \multicolumn{7}{|c|}{ Palliative care physician consulted ${ }^{2}$} \\
\hline No $(n=1210)$ & $243(90.3)$ & $16(88.9)$ & $147(92.5)$ & $152(78.8)$ & 293(60.9) & $359(71.4)$ \\
\hline Yes $(n=413)$ & $26(9.7)$ & $2(11.1)$ & $12(7.5)$ & $41(21.2)$ & $188(39.1)$ & $144(28.6)$ \\
\hline \multicolumn{7}{|c|}{$\geq 1$ home visit by a physician } \\
\hline No $(n=1328)$ & $218(81)$ & $16(88.9)$ & $100(62.9)$ & $122(63.2)$ & $426(88.6)$ & $446(88.7)$ \\
\hline Yes $(n=295)$ & $51(19)$ & $2(11.1)$ & $59(37.1)$ & $71(36.8)$ & $55(11.4)$ & $57(11.3)$ \\
\hline \multicolumn{7}{|c|}{$\geq 1$ visit in the community by a specialist ${ }^{3}$} \\
\hline No $(n=637)$ & $135(50.1)$ & $2(11.1)$ & $47(29.6)$ & $77(39.9)$ & $164(34.1)$ & $212(42.1)$ \\
\hline Yes $(n=986)$ & $134(49.9)$ & $16(88.9)$ & $112(70.4)$ & $116(60.1)$ & $317(65.9)$ & 291(57.9) \\
\hline \multicolumn{7}{|c|}{$\geq 1$ visit in the community by a general practitioner } \\
\hline No $(n=537)$ & $132(49.1)$ & $3(16.7)$ & $46(28.9)$ & $42(21.8)$ & $168(34.9)$ & $146(29)$ \\
\hline Yes $(n=1086)$ & $137(50.9)$ & $15(83.3)$ & $113(71.1)$ & $151(78.2)$ & $313(65.1)$ & $357(71)$ \\
\hline
\end{tabular}

*Percents are of the column and rounded to nearest integer

1- not including the ER visit leading to the last admission leading to death

2- all consults done during admissions (extracted from MedEcho). More than one consult per subject was accounted as one

3- Includes Neurosurgeons, Neurologists, Oncologist, and radiation oncologists 
Table 4-4: Cumulative proportional odds ratio (CPOR) estimating level of care burden (model 1) and place of death accounting for level of care burden (model 2 ) across different variables.*

\begin{tabular}{|c|c|c|c|c|}
\hline \multirow[t]{2}{*}{ Variable } & \multicolumn{2}{|c|}{ Care burden } & \multicolumn{2}{|c|}{$\begin{array}{l}\text { Place of death } \\
\text { including care } \\
\text { burden }\end{array}$} \\
\hline & CPOR & $95 \% \mathrm{CI}$ & CPOR & $95 \% \mathrm{CI}$ \\
\hline \multicolumn{5}{|c|}{ Age category (years) } \\
\hline$\leq 39$ & 1.09 & $0.74-1.62$ & 0.99 & $0.66-1.48$ \\
\hline $40-49$ & 1.12 & $0.83-1.53$ & 1.09 & $0.8-1.5$ \\
\hline $50-59$ (referent) & 1 & & 1 & \\
\hline $60-69$ & 1.21 & $0.94-1.52$ & 1.18 & $0.91-1.54$ \\
\hline $70-79$ & 1.34 & $1.03-1.75$ & 1.52 & $1.16-2$ \\
\hline$\geq 80$ & 0.9 & $0.63-1.29$ & 1.89 & $1.3-2.74$ \\
\hline \multicolumn{5}{|c|}{ Charlson Comorbidity Index } \\
\hline$\leq 1$ (referent) & 1 & & 1 & \\
\hline 2 & 1.43 & $1.14-1.8$ & 0.86 & $0.68-1.09$ \\
\hline 3 & 1.24 & $0.93-1.66$ & 1.24 & $0.92-1.67$ \\
\hline 4 & 2.02 & $1.3-3.13$ & 1.26 & $0.8-1.99$ \\
\hline$\geq 5$ & 1.82 & $1.36-2.44$ & 0.96 & $0.71-1.29$ \\
\hline
\end{tabular}

Social deprivation index (Quintile)

$\begin{array}{lcccc}1 \text { (referent) } & 1 & & 1 & \\ 2 & 1.05 & 0.79-1.39 & 0.99 & 0.75-1.33 \\ 3 & 0.99 & 0.75-1.32 & 0.96 & 0.71-1.28 \\ 4 & 1.23 & 0.92-1.64 & 1.14 & 0.85-1.54 \\ 5 & 1.27 & 0.95-1.71 & 1.24 & 0.92-1.68\end{array}$

Material deprivation index (Quintile)

\begin{tabular}{lcccc}
1 (referent) & 1 & & 1 & \\
2 & 0.9 & $0.67-1.19$ & 1.17 & $0.87-1.56$ \\
3 & 1.07 & $0.81-1.42$ & 1.09 & $0.82-1.45$ \\
4 & 1.01 & $0.76-1.35$ & 0.98 & $0.73-1.32$ \\
5 & 1.03 & $0.76-1.38$ & 1.04 & $0.77-1.42$ \\
evel of care burden & - & - & 1.15 & $1.11-1.2$ \\
linear trend)** & & & & \\
Gender & 1.05 & $0.88-1.26$ & 0.94 & $0.79-1.13$ \\
Residence & 0.94 & $0.74-1.21$ & 1.27 & $0.98-1.64$ \\
Tumor type (GBM) & 1.44 & $1.19-1.74$ & 0.74 & $0.6-0.9$ \\
\hline
\end{tabular}

* $\mathrm{P}$ values of the test for homogeneity $\left(\chi^{2}\right)$ was $>0.05$.

**Linear trend for level of care burden is per unit, which ranged from 0 to 9. 


\section{Discussion and conclusion}

In recent years, progress has been made in the management of primary intracranial tumor patients. Nevertheless, additional efforts are needed to improve supportive care and address end of life issues adequately. In general, the main goals of end of life care are to offer adequate symptom control, avoid inappropriately prolonging the dying process, and provide psychological support to meet the emotional needs of patients and caregivers, all these needs are well documented in the literature.

The knowledge about the existing health care delivery system to the terminally ill is still lacking, especially in this type of patient population, where practitioners managing care and outcomes of persons with primary intracranial tumors are facing a rare and challenging pathology.

Administrative health databases have the unique potential of providing population-based, unbiased, efficient measures of quality of care especially in countries where population-based data are available. ${ }^{9}$

This study discussed - thesis manuscript - the effect of variables that had an association with the level of care burden and place of death (age, comorbidity and tumor type). This part of the thesis will continue the discussion about other variables that were included in the analysis like the socioeconomic variables (assessed by the social and material deprivation indexes), gender, residence and affiliation with a hospital. 
Cancer patients who had higher level of socioeconomic status are more likely to die at home rather than in an institution, this is also noted when patients were classified by socioeconomic area of residence. ${ }^{79,87,88,93}$ Costantini et al ${ }^{91}$ concluded that terminal cancer patients with higher educational level were more likely to die at home than those who were less educated, others did not find any significant relationship between educational level and place of death. ${ }^{79}$

Contradictory findings were documented in the published studies of adult cancer patients regarding gender as an influencing factor on place of death; several studies demonstrated that gender is not significant for determining the place of death. ${ }^{84,85,87,89,92}$ Others suggested that women were less likely than men to die at home. ${ }^{79,88,90}$ In contrast, another study found that the proportion of home deaths was significantly higher among females than among males. ${ }^{91}$

Affiliation with a hospital was a determinant of place of death in some studies. Patients served by a hospice that had its own beds or was affiliated with a hospital were three times more likely to die in a medical setting than were patients served by hospices without beds or direct access to them. ${ }^{97}$ Thorne et al ${ }^{78}$ showed that the presence of community hospital beds was associated with a significant reduction in home deaths.

When a person dies from other than sudden or traumatic causes, the processes of care experienced by person dying appears to be a function of a complex interplay of personal and cultural values and physical and medical factors, as well as various health care systems forces. ${ }^{97}$ 
Cultural values, such as the desire " not to become a burden" the social stigma associated with death, and institutional or health-system factors such as the lack of home support services, and the convenience of providing medical treatment to patients in a hospital setting, may counterbalance expressed preferences of place of death, ${ }^{97}$ and subsequently increase level of care burden (more ER visits, high number of hospital days near the end of life, etc) in an attempt to reform this balance.

From the results of this study, suggestions can be made to improve the processes of care experienced by persons dying of primary intracranial tumors.

First, integration of palliative care within the continuum of cancer care ${ }^{98}$, by involvement of palliative care physicians or nurses early in the management plane, especially for patients with aggressive tumors (e.g. GBM) through participation in tumor board meetings, involvement in the multidisciplinary clinics, etc. This will avoid heterogeneous and late referral and subsequently reduce care burden and facilitate patient follow up.

Second, there needs to be greater access to palliative care beds (PCU/ hospice). The care of the terminally ill can be successfully transferred from acute care beds to palliative care beds and this shift in place of death is associated with a cost saving in the acute care institution which largely compensates for the cost of specialized palliative care beds. ${ }^{99}$

Third, the involvement of the general practitioner should be valued and supported. 
This would require better communication and collaboration with the cancer specialists and a transfer of care when cancer patients experience deterioration due to progression of the disease. One consideration is to involve communitybased physicians in the integrated approach discussed previously; so that the dying will be better served at the community level.

Specific studies also need to be carried out to identify the causes for the low home death rate, to address the cultural values and the social stigma associated with death at home, and specifically looking at ways to promote home visits and better provision of home care.

In conclusion, this study showed that despite valuable research efforts to improve the treatment of primary intracranial tumors that focus on tumor biology and refinements to surgery, radiation, and chemotherapy, there is also room to improve aspects of care in the end of life situation. An integrative approach for this patient's population, from diagnosis to death, could potentially reduce the care burden in the final period on the health care system, patient's family and improve access to a better place of death. 


\section{References}

1. World Health Organization Expert Committee: World Health Organization Techinica Report Series 804: . Geneva S, World Health Organization, . Cancer Pain Relief and Palliative Care. 1990.

2. SEALE CF. What happens in hospices: A review of research evidence. So Sci Med. 1989;28:551-55.

3. Higginson IJ, Finlay IG, Goodwin DM, et al. Is there evidence that palliative care teams alter end-of-life experiences of patients and their caregivers? Journal of pain and symptom management. 2003;25:15068.

4. Hearn J, Higginson IJ. Do specialist palliative care teams improve outcomes for cancer patients? A systematic literature review. Palliative medicine. 1998;12:317-32.

5. Gagnon B, Mayo NE, Hanley J, MacDonald N. Pattern of care at the end of life: does age make a difference in what happens to women with breast cancer? Journal of Clinical Oncology. 2004;22:3458-65.

6. Earle CC, Ayanian JZ. Looking back from death: the value of retrospective studies of end-of-life care. Journal of clinical oncology. 2006;24:838-40.

7. Higginson IJ, Jarman B, Astin P, Dolan S. Do social factors affect where patients die: an analysis of 10 years of cancer deaths in England. Journal of Public Health. 1999;21:22-8.

8. Iezzoni LI. Assessing quality using administrative data. Annals of internal medicine. 1997;127:666.

9. Earle CC, Park ER, Lai B, Weeks JC, Ayanian JZ, Block S. Identifying potential indicators of the quality of end-of-life cancer care from administrative data. Journal of Clinical Oncology. 2003;21:1133-8.

10. Singer PA, Wolfson M. The best places to die. BMJ. 2003;327:173-4.

11. Townsend J, Frank A, Fermont D, et al. Terminal cancer care and patients' preference for place of death: a prospective study. BMJ: British Medical Journal. 1990;301:415.

12. Hays JC, Galanos AN, Palmer TA, McQuoid DR, Flint EP. Preference for place of death in a continuing care retirement community. The Gerontologist. 2001;41:123-8.

13. Teno JM, Weitzen S, Fennell ML, Mor V. Dying trajectory in the last year of life: does cancer trajectory fit other diseases? Journal of palliative medicine. 2001;4:457-64.

14. Lunney JR, Lynn J, Foley DJ, Lipson S, Guralnik JM. Patterns of functional decline at the end of life. JAMA: the journal of the American Medical Association. 2003;289:2387-92.

15. Walker M, Brown J, Brown K, Gregor A, Whittle I, Grant R. Practical problems with the collection and interpretation of serial quality of life assessments in patients with malignant glioma. Journal of neurooncology. 2003;63:179-86. 
16. McCarthy EP, Phillips RS, Zhong Z, Drews RE, Lynn J. Dying with cancer: patients' function, symptoms, and care preferences as death approaches. Journal of the American Geriatrics Society. 2000.

17. Taillibert S, Laigle-Donadey F, Sanson M. Palliative care in patients with primary brain tumors. Current opinion in oncology. 2004;16:58792.

18. Voltz R, Borasio G. Palliative therapy in the terminal stage of neurological disease. Journal of neurology. 1997;244:2-10.

19. Quebec Gd. Healthcare and Social Services. 2013.

20. Huth EJ, Murray TJ. Medicine in quotations: views of health and disease through the ages: Amer College of Physicians; 2006.

21. Hajdu SI. A note from history: landmarks in history of cancer, part 1. Cancer. 2011;117:1097-102.

22. Hajdu SI. A note from history: landmarks in history of cancer, part 2. Cancer. 2011;117:2811-20.

23. theAmericanCancerSociety. Cancer survivorship. 2013.

24. Raven RW. The theory and practice of oncology. 1990.

25. Li JJ. Laughing gas, Viagra, and Lipitor: The human stories behind the drugs we use: Oxford University Press, USA; 2006.

26. Nixon R. State of the Union Address. 1971-1-22.

27. Potti A, Schilsky RL, Nevins JR. Refocusing the war on cancer: the critical role of personalized treatment. Science translational medicine. 2010;2.

28. Boyle P, Levin B. World cancer report 2008: IARC Press, International Agency for Research on Cancer; 2008.

29. Canada S. Mortality- summery list of causes. 2009.

30. Jemal A, Siegel R, Ward E, Hao Y, Xu J, Thun MJ. Cancer statistics, 2009. CA: a cancer journal for clinicians. 2009;59:225-49.

31. Bondy ML, Scheurer ME, Malmer B, et al. Brain tumor epidemiology: consensus from the Brain Tumor Epidemiology Consortium. Cancer. 2008;113:1953-68.

32. Wen PY, Kesari S. Malignant gliomas in adults. New England Journal of Medicine. 2008;359:492-507.

33. Batchelor TT, Byrne TN. Supportive care of brain tumor patients. Hematology/oncology clinics of North America. 2006;20.

34. Taillibert S, Delattre J-Y. Palliative care in patients with brain metastases. Current opinion in oncology. 2005;17:588-92.

35. Lidstone V, Butters E, Seed P, Sinnott C, Beynon T, Richards M. Symptoms and concerns amongst cancer outpatients: identifying the need for specialist palliative care. Palliative medicine. 2003;17:588-95.

36. Junck L. Supportive management in neuro-oncology: opportunities for patient care, teaching, and research. Current opinion in neurology. 2004;17:649-53.

37. Dolecek TA, Propp JM, Stroup NE, Kruchko C. CBTRUS statistical report: primary brain and central nervous system tumors diagnosed in the United States in 2005-2009. Neuro-oncology. 2012;14:v1-v49. 
38. States CBTRotU. CBTRUS statistical report: primary brain and central nervous system tumors diagnosed in the United States in 2004-2008 (March 23, 2012 Revision): Central Brain Tumor Registry of the United States Hinsdale, IL; 2012.

39. Committee CCSsS. Canadian Cancer Statistics 2012. Toronto:: Canadian Cancer Society.; 2012.

40. Ferlay J, Shin H, Bray F, Parkin D. GLOBOCAN 2008 v1. 2, Cancer Incidence and Mortality Worldwide: IARC CancerBase No. 10 [Internet].(International Agency for Research on Cancer, Lyon, France, 2010)2011.

41. Porter KR, McCarthy BJ, Freels S, Kim Y, Davis FG. Prevalence estimates for primary brain tumors in the United States by age, gender, behavior, and histology. Neuro-oncology. 2010;12:520-7.

42. Peter ID, Linet MS, Heineman EF. Etiology of brain tumors in adults. Epidemiologic reviews. 1995;17:382-414.

43. Wrensch M, Minn Y, Chew T, Bondy M, Berger MS. Epidemiology of primary brain tumors: current concepts and review of the literature. Neuro-oncology. 2002;4:278-99.

44. Ries LAG, Young Jr JL, Keel GE, Eisner MP, Lin YD, Horner M-JD. Cancer survival among adults: US SEER program, 1988-2001. Patient and tumor characteristics. SEER Survival Monograph. Publication. 2007:076215.

45. Bussière M, Hopman W, Day A, Pombo AP, Neves T, Espinosa F. Indicators of functional status for primary malignant brain tumour patients. The Canadian Journal of Neurological Sciences. 2005;32:50-6.

46. Field MJ, Cassel CK. Approaching death: improving care at the end of life: National Academies Press; 1997.

47. Patrick DL, Engelberg RA, Curtis JR. Evaluating the quality of dying and death. Journal of pain and symptom management. 2001;22:717-26.

48. Patrick DL, Curtis JR, Engelberg RA, Nielsen E, McCown E. Measuring and improving the quality of dying and death. Annals of Internal Medicine. 2003;139:410-5.

49. Ford E, Catt S, Chalmers A, Fallowfield L. Systematic review of supportive care needs in patients with primary malignant brain tumors. Neuro-oncology. 2012;14:392-404.

50. Jalali R, Dutta D. Factors influencing quality of life in adult patients with primary brain tumors. Neuro-oncology. 2012;14:iv8-iv16.

51. Pace A, Di Lorenzo C, Guariglia L, Jandolo B, Carapella CM, Pompili A. End of life issues in brain tumor patients. Journal of neuro-oncology. 2009;91:39-43.

52. Sizoo EM, Braam L, Postma TJ, et al. Symptoms and problems in the end-of-life phase of high-grade glioma patients. Neuro-oncology. 2010;12:1162-6.

53. Pelletier G, Verhoef MJ, Khatri N, Hagen N. Quality of life in brain tumor patients: the relative contributions of depression, fatigue, 
emotional distress, and existential issues. Journal of neuro-oncology. 2002;57:41-9.

54. Oberndorfer S, Lindeck-Pozza E, Lahrmann H, Struhal W, Hitzenberger $\mathrm{P}$, Grisold W. The end-of-life hospital setting in patients with glioblastoma. Journal of Palliative Medicine. 2008;11:26-30.

55. Brown PD, Jensen AW, Felten SJ, et al. Detrimental effects of tumor progression on cognitive function of patients with high-grade glioma. Journal of clinical oncology. 2006;24:5427-33.

56. Chaichana KL, Halthore AN, Parker SL, et al. Factors involved in maintaining prolonged functional independence following supratentorial glioblastoma resection. Journal of neurosurgery. 2011;114:604-12.

57. Schubart JR, Kinzie MB, Farace E. Caring for the brain tumor patient: family caregiver burden and unmet needs. Neuro-oncology. 2008;10:61-72.

58. Keir ST. Levels of stress and intervention preferences of caregivers of brain tumor patients. Cancer nursing. 2007;30:E33-E9.

59. Janda M, Steginga S, Dunn J, Langbecker D, Walker D, Eakin E. Unmet supportive care needs and interest in services among patients with a brain tumour and their carers. Patient education and counseling. 2008;71:251.

60. Caroline Bédard DM, Pastelle Ladouceur-Kègle. SOINS PALLIATIFS DE FIN DE VIE AU QUÉBEC : DÉFINITION ET MESURE D’INDICATEURS Institut national de santé publique du Québec. 2006

61. Becker G, Hatami I, Xander C, et al. Palliative cancer care: an epidemiologic study. Journal of Clinical Oncology. 2011;29:646-50.

62. Arber A, Faithfull S, Plaskota M, Lucas C, de Vries K. A study of patients with a primary malignant brain tumour and their carers: symptoms and access to services. International Journal of Palliative Nursing. 2010;16:24-30.

63. Faithfull S, Cook K, Lucas C. Palliative care of patients with a primary malignant brain tumour: case review of service use and support provided. Palliative medicine. 2005;19:545-50.

64. Higginson IJ. Priorities and preferences for end of life care in England, Wales and Scotland. National Council for Hospice and Specialist Palliative Care Services, London. 2003.

65. Catt SL, Anderson JL, Chalmers AJ, Fallowfield LJ. A UK - wide survey of follow - up practices for patients with high - grade glioma treated with radical intent. Journal of evaluation in clinical practice. 2011;17:1-6.

66. Gofton TE, Jog MS, Schulz V. A palliative approach to neurological care: a literature review. The Canadian Journal of Neurological Sciences. 2009;36:296-302.

67. Tamblyn R, Reid T, Mayo N, McLeod P, Churchill-Smith M. Using medical services claims to assess injuries in the elderly: sensitivity of 
diagnostic and procedure codes for injury ascertainment. Journal of clinical epidemiology. 2000;53:183-94.

68. Gagnon B, Mayo NE, Laurin C, Hanley JA, McDonald N. Identification in administrative databases of women dying of breast cancer. Journal of clinical oncology. 2006;24:856-62.

69. Eton DT, de Oliveira DR, Egginton JS, et al. Building a measurement framework of burden of treatment in complex patients with chronic conditions: a qualitative study. Patient related outcome measures. 2012;3:39.

70. Romano PS, Roost LL, Jollis JG. Presentation adapting a clinical comorbidity index for use with ICD-9-CM administrative data: differing perspectives. Journal of clinical epidemiology. 1993;46:10759.

71. Pampalon R, Hamel D, Gamache P, Raymond G. A deprivation index for health planning in Canada. Chronic diseases in Canada. 2009;29:17891.

72. Scott SC, Goldberg MS, Mayo NE. Statistical assessment of ordinal outcomes in comparative studies. J Clin Epidemiol. 1997;50:45-55.

73. Tang ST, McCorkle R. Determinants of place of death for terminal cancer patients. Cancer investigation. 2001;19:165-80.

74. Flechl B, Ackerl M, Sax C, et al. The caregivers' perspective on the endof-life phase of glioblastoma patients. Journal of neuro-oncology. 2013;112:403-11.

75. Simon ST, Gomes B, Koeskeroglu P, Higginson IJ, Bausewein C. Population, mortality and place of death in Germany (1950-2050) implications for end-of-life care in the future. Public health. 2012;126:937-46.

76. Fukui S, Kawagoe H, Masako S, Noriko N, Hiroko N, Toshie M. Determinants of the place of death among terminally ill cancer patients under home hospice care in Japan. Palliative medicine. 2003;17:445-53.

77. Murray MA, Fiset V, Young S, Kryworuchko J. Where the dying live: a systematic review of determinants of place of end-of-life cancer care. Paper presented at: Oncology nursing forum2009.

78. Thorne CP, Seamark DA, Lawrence C, Gray DJ. The influence of general practitioner community hospitals on the place of death of cancer patients. Palliat Med. 1994;8:122-8.

79. De Conno F, Caraceni A, Groff L, et al. Effect of home care on the place of death of advanced cancer patients. European journal of cancer. 1996;32A:1142-7.

80. Pritchard RS, Fisher ES, Teno JM, et al. Influence of patient preferences and local health system characteristics on the place of death. SUPPORT Investigators. Study to Understand Prognoses and Preferences for Risks and Outcomes of Treatment. Journal of the American Geriatrics Society. 1998;46:1242. 
81. Agences statistique fédérales du canada,Nombre de lits d'hôpitaux pour 1000 habitants. Montreal, Canada. Institut de la statistique Quebec, Gouvernement du Canada,Gouvernement du Québec. 2002.

82. Baumann AO, Deber RB, Silverman BE, Mallette CM. Who cares? Who cures? The ongoing debate in the provision of health care. Journal of advanced nursing. 1998;28:1040-5.

83. Tran V-T, Montori VM, Eton DT, Baruch D, Falissard B, Ravaud P. Development and description of measurement properties of an instrument to assess treatment burden among patients with multiple chronic conditions. BMC medicine. 2012;10:68.

84. Soukop M, Calman K. Cancer patients: where they die-an analysis. Practitioner. 1977;219:883-8.

85. Bass DM, Pestello EP, Garland TN. Experiences with home hospice care: determinants of place of death. Death education. 1984;8:199222.

86. De Conno F, Caraceni A, Groff L, et al. Effect of home care on the place of death of advanced cancer patients. European journal of cancer. 1996;32:1142-7.

87. McCusker J. Where cancer patients die: an epidemiologic study. Public health reports. 1983;98:170-6.

88. Hunt R, Bonett A, Roder D. Trends in the terminal care of cancer patients: South Australia, 1981-1990. Australian and New Zealand journal of medicine. 1993;23:245-51.

89. Axelsson B, Christensen SB. Place of death correlated to sociodemographic factors. A study of 203 patients dying of cancer in a rural Swedish county in 1990. Palliat Med. 1996;10:329-35.

90. Clifford CA, Jolley DJ, Giles GG. Where people die in Victoria. The Medical journal of Australia. 1991;155:446-51, 56.

91. Costantini M, Camoirano E, Madeddu L, Bruzzi P, Verganelli E, Henriquet F. Palliative home care and place of death among cancer patients: a population-based study. Palliat Med. 1993;7:323-31.

92. Malden LT, Sutherland C, Tattersall MH, et al. Dying of cancer. Factors influencing the place of death of patients. The Medical journal of Australia. 1984;141:147-50.

93. Catalan-Fernandez J, Pons-Sureda O, Recober-Martinez A, et al. Dying of cancer: The place of death and family circumstances. Medical care. 1991;29:841.

94. Nerenz DR. Capacities and limitations of information systems as data sources on quality of care at the end of life. J Pain Symptom Manage. 2001;22:773-83.

95. Allan DE, Stajduhar KI, Reid RC. The uses of provincial administrative health databases for research on palliative care: Insights from British Columbia, Canada. BMC palliative care. 2005;4:2.

96. Iezzoni LI. Assessing quality using administrative data. Ann Intern Med. 1997;127:666-74. 
97. Mor V, Hiris J. Determinants of site of death among hospice cancer patients. Journal of health and social behavior. 1983;24:375-85.

98. Bruera E, Hui D. Conceptual models for integrating palliative care at cancer centers. Journal of Palliative Medicine. 2012;15:1261-9.

99. Bruera E, Neumann CM, Gagnon B, Brenneis C, Quan H, Hanson J. The impact of a regional palliative care program on the cost of palliative care delivery. Journal of palliative medicine. 2000;3:181-6. 


\section{Appendices}

\section{Appendix 1: Quality of End of Life Care, Quality of Life at the End of Life, and Quality of Dying and Death: Concepts and Domains ${ }^{48}$}

Quality of end of life care

-Continuous healing relationships through death and after death for loved ones

-Focus on the dying patient's needs and respect for treatment and dying preferences

-The dying patient as source of control whenever possible; loved ones involved at all times

-Shared knowledge and information about prognosis and all aspects of care up to death

-Shared decision making based on evidence

-Transparency in care and decision processes

-Anticipation of individual needs both inside and outside care settings

-Cooperation and communication among providers

-Coordination among caregivers, patients, and families

Quality of life at the end of life

-Physical

Self care

Activities of daily living

Walking

Mobility

Eating 
Sleeping

-Psychosocial

Interaction with loved ones

Receiving and giving help

Contribution to community

Recreation

Sexual life

Income

Respect

Variety in life

-Cognitive and communication

Thinking and remembering, speaking

-Overall happiness

Quality of dying and death

-Symptoms and personal care

-Preparation for end of life

-Moment of death

-Family

-Treatment preferences

-Whole-person concerns, meaning and purpose 
Appendix 2: ICD-9 and ICD-10 codes defining included persons with a single intracranial tumor.

\begin{tabular}{ll}
\hline & ICD-9 codes \\
\hline Malignant neoplasm of brain & $191.0-191.9$ \\
Malignant neoplasm of cranial nerves & 192.0 \\
Malignant neoplasm of cerebral meninges & 192.1 \\
Benign neoplasm of brain, cranial nerves and cerebral & $225.0-225.2$ \\
meninges & \\
\hline $\begin{array}{l}\text { Malignant neoplasm of cerebral meninges } \\
\text { Malignant neoplasm of brain }\end{array}$ & C70.10 codes \\
Malignant neoplasm of cerebral meninges & C71.0- C71.9 \\
Malignant neoplasm of Pituitary gland & C72.2- C72.5 \\
$\begin{array}{l}\text { Benign neoplasm of cerebral meninges } \\
\text { Benign neoplasm of brain and cranial nerves }\end{array}$ & C75.1 \\
$\begin{array}{l}\text { Benign neoplasm of Pituitary gland } \\
\text { Neoplasms of uncertain or unknown behavior of }\end{array}$ & D33.0 and D32.9- D33.3 \\
meninges & D35.2 \\
$\begin{array}{l}\text { Neoplasms of uncertain or unknown behavior of brain } \\
\text { and CNS }\end{array}$ & D43.0 and D42.9 D43.3 and D44.3 \\
\hline
\end{tabular}




\begin{tabular}{ll}
$\begin{array}{l}\text { Appendix 3: Histology codes defining included persons with primary } \\
\text { intracranial tumors. }\end{array}$ \\
\hline \multicolumn{2}{c}{ TCDO-3 Histology code } \\
\hline \multicolumn{2}{c}{ Tumors of Neuroepithelial Tissue } \\
\hline Pilocytic astrocytoma & 9421 \\
Protoplasmic \& fibrillary astrocytoma & 9410,9420 \\
Anaplastic astrocytoma & 9401,9411 \\
Unique astrocytoma variants & $9383,9384,9424$ \\
Astrocytoma, NOS & 9400 \\
Glioblastoma & $9440,9441,9442 / 3 \mathrm{c}$ \\
Oligodendroglioma & 9450 \\
Anaplastic oligodendroglioma & 9451,9460 \\
Ependymoma/anaplastic ependymoma & $9391,9392,9393$ \\
Ependymoma variants & 9394 \\
Mixed glioma & 9382 \\
Glioma malignant, NOS & 9380 \\
Choroid plexus & 9390 \\
Neuroepithelial & $9381,9423,9430,9444$ \\
Non-malignant and malignant neuronal/glial, & $8680,8681,8682,8690,8693,9412$, \\
& $9413,9442 / 1 \mathrm{~d}, 9490,9491$, \\
Neuronal and mixed & $9492,9493,9500,9505,9506,9522$, \\
& 9523 \\
Pineal parenchymal & $9360,9361,9362$ \\
Embryonal/primitive/medulloblastoma & $8901,8921,8963,9363,9364,9470$, \\
& $9471,9472,9473,9474$, \\
&
\end{tabular}

\begin{tabular}{lc}
\hline \multicolumn{2}{c}{ Tumors of Cranial Nerves } \\
\hline Nerve sheath, non-malignant and malignant & $9540,9541,9550,9560,9561,9570$, \\
& 9571 \\
Other tumors of cranial and spinal nerves & 9562 \\
\hline \multicolumn{2}{c}{ Tumors of Meninges } \\
\hline Meningioma & $9530,9531,9532,9533,9534,9537$, \\
& 9538,9539 \\
Other mesenchymal, non-malignant and & $8324,8728,8800,8801,8802,8803$, \\
& $8804,8805,8806,8810,8815,8824$, \\
Malignant & 8830 \\
& $8831,8835,8836,8850,8851,8852$, \\
& $8853 \mathrm{e}, 8854,8857,8861,8870,8890$, \\
& $8897,8900,8910,8912,9260,9480$, \\
Hemangioblastoma & $9536,8920,8935,8990,9040,9136$, \\
& $9150,9170,9180,9210,9241$ \\
& 9161,9535 \\
\hline Lymphoma & $9590,9591,9596,9650,9651,9652$, \\
& $9653,9654,9655,9659,9661,9662$, \\
& $9663,9664,9665,9667,9670,9671$, \\
$9673,9675,9680,9684,9687,9690$, \\
909
\end{tabular}




\begin{tabular}{lc}
\hline & $9826,9827,9860,9861,9930,9970$ \\
\hline Germ cell tumors, cysts and heterotopias & $8020,8440,9060,9061,9064,9065$, \\
& $9070,9071,9072,9080,9081,9082$, \\
& $9083,9084,9085,9100,9101$ \\
\hline Tumors of Sellar Region \\
\hline Pituitary & $8022,8040,8140,8146,8190,8202$, \\
& $8240,8246,8260,8270,8271,8272$, \\
& $8280,8281,8290,8300,8310,8320$, \\
Craniopharyngioma & $8323,8333,8334,8341,9582$ \\
& $9350,9351,9352$ \\
\hline Chordoma/chondrosarcoma & Local Extensions from Regional Tumors \\
& $9220,9231,9240,9370,9371,9372$, \\
\hline & 9373 \\
\hline Hemangioma & Unclassified Tumors \\
All others & $9120,9121,9122,9123,9125,9130$, \\
\hline
\end{tabular}




\section{Appendix 4: Codes defining included persons with complication of primary intracranial tumors.}

\begin{tabular}{|c|c|c|}
\hline $\begin{array}{l}\text { Final diagnosis included any one } \\
\text { of the following: }\end{array}$ & ICD-9 codes & ICD-10 codes \\
\hline \multicolumn{3}{|c|}{ Septic complications } \\
\hline Septicemia & $38.0-38.9$ & $\begin{array}{l}\text { A } 39.0-\mathrm{A} 39.9 \\
\text { A } 40.0-\mathrm{A} 40.9\end{array}$ \\
\hline Other bacterial infection & $41.0-41.9$ & $\begin{array}{l}\text { A } 41.0-\mathrm{A} 41.9 \\
\text { A } 49.0-\mathrm{A} 49.9\end{array}$ \\
\hline Pneumonia & $481.0-486.9$ & $\mathrm{~J} 13, \mathrm{~J} 14, \mathrm{~J} 15, \mathrm{~J} 16, \mathrm{~J} 17, \mathrm{~J} 18$ \\
\hline \multicolumn{3}{|c|}{ Hematologic complication } \\
\hline Anemia & $280.0-280.9$ & $\begin{array}{l}\text { D50, D51, D52, D53, D59, } \\
\text { D63, D65 }\end{array}$ \\
\hline Neutropenia & 288.0 & D70 \\
\hline Plasma protein disorder & $273.1,273.9$ & $\begin{array}{l}\text { R77.0, R77.1 R77.2, R77.8 } \\
\text { R77.9 }\end{array}$ \\
\hline Thrombosis (arteral and venous) & $451.0-453.9$ & $\mathrm{I} 26, \mathrm{I} 74, \mathrm{I} 75, \mathrm{I} 76, \mathrm{I} 80, \mathrm{I} 82$ \\
\hline $\begin{array}{l}\text { Thrombophlebitis of intracranial } \\
\text { venous sinuses }\end{array}$ & $325.0-325.9$ & \\
\hline Cerebrovascular events & $430.0-438.9$ & $\begin{array}{l}\text { I60, I61, I62, I63, I64, I65, } \\
\text { I66, I67, I68, I69 }\end{array}$ \\
\hline \multicolumn{3}{|c|}{ Electrolytic complications } \\
\hline Electrolyte disorders & $276.0-276.9$ & E83 \\
\hline Hypercalcemia & 275.4 & \\
\hline \multicolumn{3}{|c|}{ Stress induced } \\
\hline Gastric and duodenal peptic ulcer & $531.0-535.9$ & K25.0-K25.9 \\
\hline Gastrointestinal hemorrhage & $578.0-578.9$ & $\begin{array}{l}\text { K26.0-K26.9 } \\
\text { K27.0-K27.9 } \\
\text { K28.0-K28.9 }\end{array}$ \\
\hline \multicolumn{3}{|c|}{ End-stage complications } \\
\hline Nonsenile organic brain syndrome & $292.0-293.9$ & $\begin{array}{l}\text { F05, F11, F13, F19, F41, } \\
\text { F43, F54 }\end{array}$ \\
\hline Secondary damage to brain & $348.1-348.9$ & G91, G93, G97, \\
\hline Unspecified cardiac arrhythmia & 427.9 & I49 \\
\hline Unspecified bowel obstruction & 560.9 & K56.60, K56.69 \\
\hline Unspecified renal failure & $586.0-586.9$ & $\mathrm{~N} 17.9, \mathrm{~N} 18.9$ \\
\hline Chronic ulcer of the skin & $707.0-707.9$ & L89 \\
\hline Symptoms & $780.0-789.9$ & R00-R99 \\
\hline Nonspecific abnormal findings & $790.0-796.9$ & T80-T88 \\
\hline Ill-defined causes of mortality & $799.0-799.9$ & Y62-Y84 \\
\hline Specific procedures and aftercare & V53.4-V58.4 & Z00-Z08, Z12 \\
\hline Persons in other circumstances & V60.0-V64.9 & Z40-Z51 \\
\hline
\end{tabular}


Appendix 5: Number of subjects per care burden estimate.

\begin{tabular}{ll}
\hline Estimated care burden & Number of subjects \\
\hline 0 & 90 \\
1 & 200 \\
2 & 301 \\
3 & 260 \\
4 & 242 \\
5 & 190 \\
6 & 159 \\
7 & 81 \\
8 & 47 \\
9 & 31 \\
10 & 14 \\
11 & 4 \\
12 & 1 \\
13 & 3 \\
\hline
\end{tabular}

